\title{
Modeling canopy-induced turbulence in the Earth system: a unified parameterization of turbulent exchange within plant canopies and the roughness sublayer (CLM-ml v0)
}

\author{
Gordon B. Bonan ${ }^{1}$, Edward G. Patton ${ }^{1}$, Ian N. Harman ${ }^{2}$, Keith W. Oleson ${ }^{1}$, John J. Finnigan ${ }^{2}$, Yaqiong Lu ${ }^{1}$, and \\ Elizabeth A. Burakowski ${ }^{3}$ \\ ${ }^{1}$ National Center for Atmospheric Research, P.O. Box 3000, Boulder, Colorado, USA 80307 \\ ${ }^{2}$ CSIRO Oceans and Atmosphere, Canberra, Australia \\ ${ }^{3}$ Institute for the Study of Earth, Oceans, and Space, University of New Hampshire, Durham, New Hampshire, USA
}

Correspondence: Gordon B. Bonan (bonan@ucar.edu)

Received: 16 October 2017 - Discussion started: 20 November 2017

Revised: 20 February 2018 - Accepted: 7 March 2018 - Published: 16 April 2018

\begin{abstract}
Land surface models used in climate models neglect the roughness sublayer and parameterize within-canopy turbulence in an ad hoc manner. We implemented a roughness sublayer turbulence parameterization in a multilayer canopy model (CLM-ml v0) to test if this theory provides a tractable parameterization extending from the ground through the canopy and the roughness sublayer. We compared the canopy model with the Community Land Model (CLM4.5) at seven forest, two grassland, and three cropland AmeriFlux sites over a range of canopy heights, leaf area indexes, and climates. CLM4.5 has pronounced biases during summer months at forest sites in midday latent heat flux, sensible heat flux, gross primary production, nighttime friction velocity, and the radiative temperature diurnal range. The new canopy model reduces these biases by introducing new physics. Advances in modeling stomatal conductance and canopy physiology beyond what is in CLM4.5 substantially improve model performance at the forest sites. The signature of the roughness sublayer is most evident in nighttime friction velocity and the diurnal cycle of radiative temperature, but is also seen in sensible heat flux. Withincanopy temperature profiles are markedly different compared with profiles obtained using Monin-Obukhov similarity theory, and the roughness sublayer produces cooler daytime and warmer nighttime temperatures. The herbaceous sites also show model improvements, but the improvements are related less systematically to the roughness sublayer parameterization in these canopies. The multilayer canopy with the roughness sublayer turbulence improves simulations com-
\end{abstract}

pared with CLM4.5 while also advancing the theoretical basis for surface flux parameterizations.

\section{Introduction}

Distinct parameterizations of land surface processes, separate from the atmospheric physics, were coupled to global climate models in the mid-1980s with the BiosphereAtmosphere Transfer Scheme (BATS; Dickinson et al., 1986) and the Simple Biosphere Model (SiB; Sellers et al., 1986). While carbon cycle feedbacks have since gained prominence in terms of model development and study of biotic feedbacks with climate change (Friedlingstein et al., 2006, 2014), the fundamental coupling between plants and the atmosphere in climate models still occurs with the fluxes of momentum, energy, and mass over the diurnal cycle as mediated by plant physiology, the microclimate of plant canopies, and boundary layer processes. The central paradigm of land surface models, as originally devised by Deardorff (1978) and carried forth with BATS, SiB, and subsequent models, has been to represent plant canopies as a homogeneous "big leaf" without vertical structure, though with separate fluxes for vegetation and soil. A critical advancement was to analytically integrate leaf physiological processes over profiles of light and nitrogen in the canopy (Sellers et al., 1996) and to extend the canopy to two big leaves to represent sunlit and 

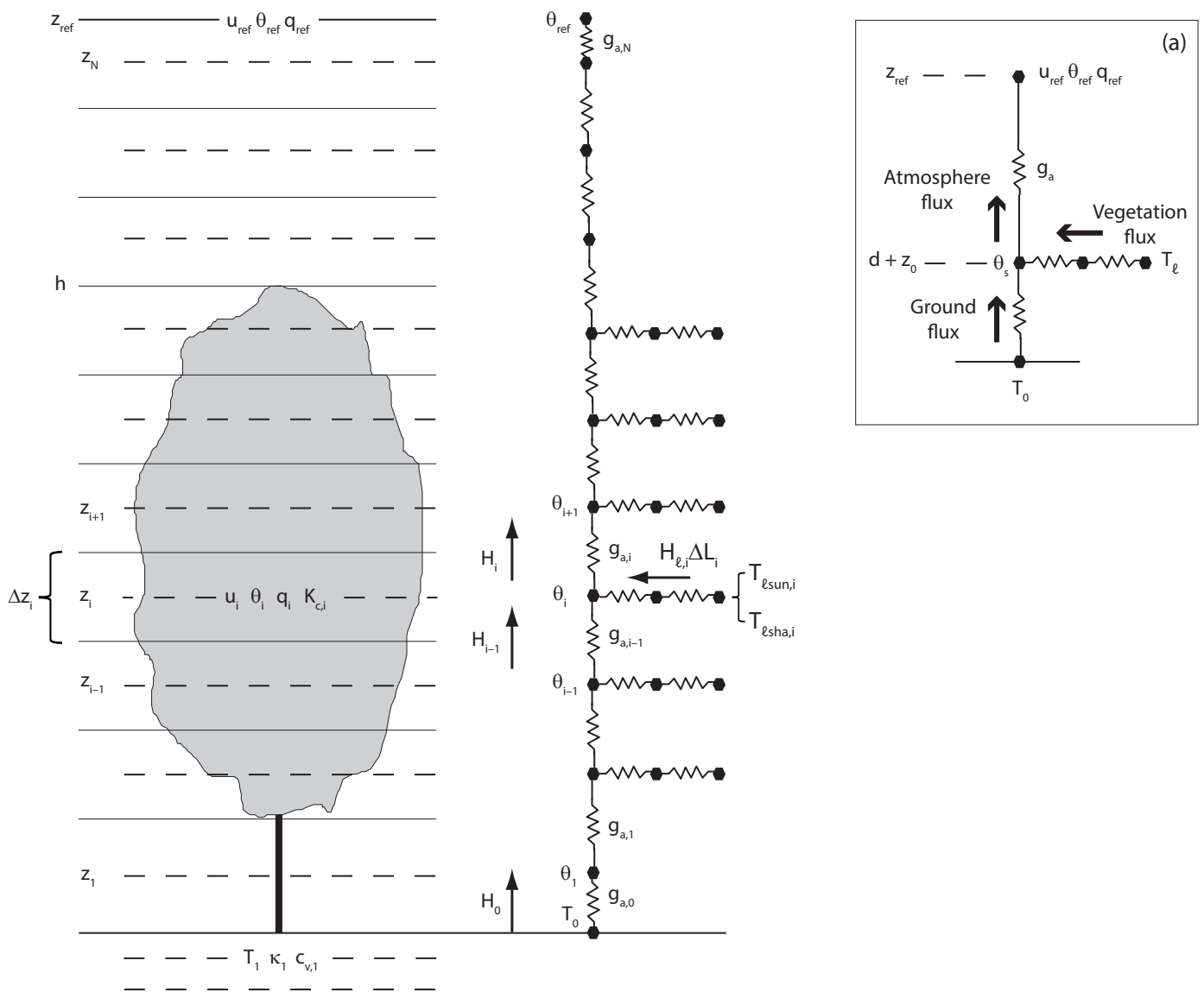

Figure 1. Numerical grid used to represent a multilayer canopy. The volume of air from the reference height $\left(z_{\text {ref }}\right)$ to the ground consists of $N$ layers with a thickness $\Delta z_{i}$, plant area index $\Delta L_{i}$, and plant area density $a_{i}=\Delta L_{i} / \Delta z_{i}$. The canopy has a height $h$. Wind speed $\left(u_{i}\right)$, temperature $\left(\theta_{i}\right)$, water vapor concentration $\left(q_{i}\right)$, and scalar diffusivity $\left(K_{\mathrm{c}, i}\right)$ are physically centered in each layer at height $z_{i}$. An aerodynamic $\left(g_{\mathrm{a}, i}\right)$ regulates the turbulent flux between layer $i$ and $i+1$. The right-hand side of the figure depicts the sensible heat fluxes below and above layer $i\left(H_{i-1}\right.$ and $\left.H_{i}\right)$ and the total vegetation source-sink flux $\left(H_{\ell, i} \Delta L_{i}\right)$ with sunlit and shaded components. Shown is the conductance network, in which nodal points represent scalar values in the air and at the leaf. Canopy source-sink fluxes depend on leaf conductances and leaf temperature, calculated separately for sunlit and shaded leaves using the temperatures $T_{\ell \text { sun, } i}$ and $T_{\ell \text { sha, } i}$, respectively. The ground is an additional source-sink of heat and water vapor with temperature $T_{0}$. The inset panel (a) shows the dual-source canopy model used in the Community Land Model (CLM4.5). Here, Monin-Obukhov similarity theory provides the flux from the surface with height $d+z_{0}$ (displacement height $d$ plus roughness length $z_{0}$ ) and temperature $\theta_{\mathrm{S}}$ to the reference height with the conductance $g_{\mathrm{a}}$. In CLM4.5, $d$ and $z_{0}$ are prescribed fractions of canopy height.

shaded portions of the canopy (Wang and Leuning, 1998; Dai et al., 2004).

In land surface models such as the Community Land Model (CLM4.5; Oleson et al., 2013), for example, fluxes of heat and moisture occur from the leaves to the canopy air, from the ground to the canopy air, and from the canopy air to the atmosphere (Fig. 1a). The flux from the canopy to the atmosphere is parameterized using Monin-Obukhov similarity theory (MOST). This theory requires the displacement height $(d)$ and roughness length $\left(z_{0}\right)$. A challenge has been to specify these, which are complex functions of the flow and physical canopy structure (Shaw and Pereira, 1982); simple parameterizations calculate them as a fixed fraction of canopy height (as in CLM4.5) or use relationships with leaf area in- dex (Sellers et al., 1986; Choudhury and Monteith, 1988; Raupach, 1994). An additional challenge, largely ignored in land surface models, is that MOST fails in the roughness sublayer (RSL) extending to twice the canopy height or more (Garratt, 1978; Physick and Garratt, 1995; Harman and Finnigan, 2007, 2008). While MOST successfully relates mean gradients and turbulent fluxes in the surface layer above the RSL, flux-profile relationships within the RSL differ from MOST. Dual-source land surface models also require parameterization of turbulent processes within the canopy. Following BATS (Dickinson et al., 1986), CLM4.5 uses an ad hoc parameterization without explicitly representing turbulence. Wind speed within the canopy is taken as equal to the friction velocity $\left(u_{*}\right)$, and the aerodynamic conductance 
between the ground and canopy air is proportional to $u_{*}$. Zeng et al. (2005) subsequently modified this expression to account for sparse and dense canopies.

Harman and Finnigan $(2007,2008)$ proposed a formulation by which traditional MOST can be modified to account for the RSL. Their theoretical derivations couple the abovecanopy turbulent fluxes with equations for the mass and momentum balances within the canopy. They tested the theory with observations for eucalyptus and pine forests, and observations above a walnut orchard further support the theory (Shapkalijevski et al., 2016). Harman (2012) examined the consequences of the RSL in a bulk surface flux parameterization coupled to an atmospheric boundary layer model. Here, we implement and test the theory in a multilayer canopy model (Bonan et al., 2014). The development of a multilayer canopy for the ORCHIDEE land surface model has renewed interest in the practical use of multilayer models (Ryder et al., 2016; Chen et al., 2016). The earlier multilayer model development of Bonan et al. (2014) focused on linking stomatal conductance and plant hydraulics and neglected turbulent processes in the canopy. The current work extends the model to include canopy-induced turbulence. The RSL theory avoids a priori specification of $z_{0}$ and $d$ by linking these to canopy density and characteristics of the flow; provides consistent forms for various turbulent terms above and within the canopy (friction velocity, wind speed, scalar transfer coefficients); and provides a method for determining the associated profiles of air temperature and water vapor concentration within the canopy.

This study is motivated by the premise that land surface models generally neglect canopy-induced turbulence, that inclusion of this is critical to model simulations, and that the Harman and Finnigan (2007, 2008) RSL theory provides a tractable parameterization extending from the ground through the canopy and the RSL. We show that the resulting within-canopy profiles of temperature, humidity, and wind speed are a crucial aspect of the leaf-to-canopy flux scaling. The previous model development of Bonan et al. (2014) included improvements to stomatal conductance and canopy physiology compared with CLM4.5. We contrast those developments with the RSL parameterization described herein and compare tall forest with short herbaceous vegetation to ascertain which aspects of the multilayer canopy most improve the model.

\section{Model description}

The canopy model has three main components: leaf gas exchange and plant hydraulics; a numerical solution for scalar profiles within and above the canopy; and inclusion of the RSL parameterization. It builds upon the work of Bonan et al. (2014), which describes leaf gas exchange and plant hydraulics for a multilayer canopy with sunlit and shaded leaves at each layer in the canopy. The calculation of leaf tempera- ture and fluxes is solved simultaneously with stomatal conductance, photosynthesis, and leaf water potential in an iterative calculation. This method numerically optimizes wateruse efficiency within the constraints imposed by plant water uptake to prevent leaf desiccation using the methodology of Williams et al. (1996). Radiative transfer of visible, nearinfrared, and longwave radiation is calculated at each level and accounts for forward and backward scattering within the canopy. Bonan et al. (2014) used the radiative transfer model of Norman (1979). We retain that parameterization for longwave radiation, but radiative transfer in the visible and near-infrared wavebands is calculated from the two-stream approximation with the absorbed solar radiation partitioned into direct beam, scattered direct beam, and diffuse radiation for sunlit and shaded leaves in relation to cumulative plant area index as in Dai et al. (2004). This allows better comparison with CLM4.5, which uses the canopy-integrated twostream solution for sunlit and shaded leaves. Soil fluxes are calculated using the layer of canopy air immediately above the ground. Temperature, humidity, and wind speed in the canopy are calculated using a bulk canopy airspace. Bonan et al. (2014) provide further details.

Here, we describe the formulation of the scalar profiles and the RSL, which were not included in Bonan et al. (2014) and which replace the bulk canopy airspace parameterization. Figure 1 shows the numerical grid. The implementation is conceptually similar to the multilayer canopy in ORCHIDEE-CAN and that model's implicit numerical coupling of leaf fluxes and scalar profiles (Ryder et al., 2016; Chen et al., 2016). That numerical scheme is modified here to include sunlit and shaded leaves at each layer in the canopy and also the RSL (Harman and Finnigan, 2007, 2008). Whereas ORCHIDEE-CAN uses an implicit calculation of longwave radiative transfer for the leaf energy balance, we retain the Norman (1979) radiative transfer used by Bonan et al. (2014). The grid spacing $(\Delta z)$ is $0.5 \mathrm{~m}$ for forest and $0.1 \mathrm{~m}$ for crop and grassland. We use thin layers to represent the light gradients that drive variation in leaf water potential in the canopy as in Bonan et al. (2014). Indeed, it is this strong variation in leaf water potential from the top of the canopy to the bottom that motivates the need for a multilayer canopy. Appendix A provides a complete description of the canopy model, and Appendix B lists all model variables.

\subsection{The coupled flux-profile equations}

In the volume of air extending from the ground to some reference height above the canopy, the scalar conservation equations for heat and water vapor, the energy balances of the sunlit and shaded canopy, and the ground energy balance provide a system of equations that can be solved for air temperature, water vapor concentration, sunlit and shaded leaf temperatures, and ground temperature. The scalar conservation equation for heat relates the change over some time interval of air temperature $(\theta, \mathbf{K})$ at height $z(\mathrm{~m})$ to the source-sink 
fluxes of sensible heat from the sunlit and shaded portions of the canopy ( $H_{\ell \text { sun }}$ and $H_{\ell \text { sha }}, \mathrm{W} \mathrm{m}^{-2}$ ) and the vertical flux divergence $\left(\partial H / \partial z, \mathrm{~W} \mathrm{~m}^{-3}\right)$. For a vertically resolved canopy, the one-dimensional conservation equation for temperature is

$$
\begin{aligned}
& \rho_{\mathrm{m}} c_{\mathrm{p}} \frac{\partial \theta(z)}{\partial t}+\frac{\partial H}{\partial z}= \\
& {\left[H_{\ell \operatorname{sun}}(z) f_{\text {sun }}(z)+H_{\ell \text { sha }}(z)\left\{1-f_{\text {sun }}(z)\right\}\right] a(z) .}
\end{aligned}
$$

The equivalent equation for water vapor $\left(q, \mathrm{~mol} \mathrm{~mol}^{-1}\right)$ in relation to the canopy source-sink fluxes $\left(E_{\ell \text { sun }}\right.$ and $E_{\ell \text { sha }}$, mol $\left.\mathrm{H}_{2} \mathrm{O} \mathrm{m}^{-2} \mathrm{~s}^{-1}\right)$ and vertical flux divergence $(\partial E / \partial z$, $\left.\mathrm{mol} \mathrm{H}_{2} \mathrm{O} \mathrm{m}^{-3} \mathrm{~s}^{-1}\right)$ is

$$
\begin{aligned}
& \rho_{\mathrm{m}} \frac{\partial q(z)}{\partial t}+\frac{\partial E}{\partial z}= \\
& {\left[E_{\ell \operatorname{sun}}(z) f_{\text {sun }}(z)+E_{\ell \text { sha }}(z)\left\{1-f_{\text {sun }}(z)\right\}\right] a(z) .}
\end{aligned}
$$

In this notation, $\rho_{\mathrm{m}}$ is molar density $\left(\mathrm{mol} \mathrm{m}^{-3}\right)$ and $c_{\mathrm{p}}$ is the specific heat of air $\left(\mathrm{J} \mathrm{mol}^{-1} \mathrm{~K}^{-1}\right), a(z)$ is the plant area density, which is equal to the leaf and stem area increment of a canopy layer divided by the thickness of the layer $\left(\Delta L(z) / \Delta z ; \mathrm{m}^{2} \mathrm{~m}^{-3}\right)$, and $f_{\text {sun }}$ is the sunlit fraction of the layer. As in Harman and Finnigan (2007, 2008), the vertical fluxes are parameterized using a first-order turbulence closure ( $K$ theory) whereby the sensible heat flux is

$H(z)=-\rho_{\mathrm{m}} c_{\mathrm{p}} K_{\mathrm{c}}(z) \frac{\partial \theta}{\partial z}$

and the water vapor flux is

$$
E(z)=-\rho_{\mathrm{m}} K_{\mathrm{c}}(z) \frac{\partial q}{\partial z}
$$

with $K_{\mathrm{c}}$ the scalar diffusivity $\left(\mathrm{m}^{2} \mathrm{~s}^{-1}\right)$, assumed to be the same for heat and water vapor as is common in land surface models, though there are exceptions (e.g., Shapkalijevski et al., 2016). These equations apply above and within the canopy, but with $a(z)=0$ for layers without vegetation. Fluxes above the canopy are obtained from MOST fluxgradient relationships as modified for the RSL, and $K_{\mathrm{c}}$ within the canopy is obtained from the momentum and scalar balance equations for plant canopies (Sect. 2.2).

The source-sink fluxes of sensible heat and water vapor are described by the energy balance equation and are provided separately for sunlit and shaded fractions of the canopy layer. The energy balance of sunlit leaves at height $z$ in the canopy is

$$
\begin{aligned}
& c_{\mathrm{L}}(z) \frac{\partial T_{\ell \operatorname{sun}}(z)}{\partial t} \Delta L_{\mathrm{sun}}(z)= \\
& {\left[R_{\mathrm{n} \ell \operatorname{sun}}(z)-H_{\ell \operatorname{sun}}(z)-\lambda E_{\ell \operatorname{sun}}(z)\right] \Delta L_{\operatorname{sun}}(z) .}
\end{aligned}
$$

The left-hand side is the storage of heat $\left(\mathrm{W} \mathrm{m}^{-2}\right)$ in a layer of vegetation with heat capacity $c_{\mathrm{L}}\left(\mathrm{J} \mathrm{m}^{-2} \mathrm{~K}^{-1}\right)$, temperature
$T_{\ell \text { sun }}(\mathrm{K})$, and plant area index $\Delta L_{\text {sun }}=f_{\text {sun }} \Delta L\left(\mathrm{~m}^{2} \mathrm{~m}^{-2}\right)$. The right-hand side is the balance between net radiation ( $R_{\mathrm{n} \ell \text { sun }}$; positive denotes energy gain), sensible heat flux ( $H_{\ell \text { sun }}$; positive away from the leaf), and latent heat flux $\left(\lambda E_{\ell \text { sun }} ;\right.$ positive away from the leaf). The sensible heat flux is

$H_{\ell \text { sun }}(z)=2 c_{\mathrm{p}}\left[T_{\ell \operatorname{sun}}(z)-\theta(z)\right] g_{\mathrm{b}}(z)$

and the evapotranspiration flux is

$E_{\ell \operatorname{sun}}(z)=\left[q_{\text {sat }}\left(T_{\ell \text { sun }}\right)-q(z)\right] g_{\ell \operatorname{sun}}(z)$.

For sensible heat, $g_{\mathrm{b}}$ is the leaf boundary layer conductance $\left(\mathrm{mol} \mathrm{m} \mathrm{m}^{-2} \mathrm{~s}^{-1}\right)$, and the factor 2 appears because heat transfer occurs from both sides of plant material. The evapotranspiration flux depends on the saturated water vapor concentration of the leaf, which varies with leaf temperature and is denoted as $q_{\text {sat }}\left(T_{\ell \text { sun }}\right)$. It also requires a leaf conductance ( $g_{\ell \text { sun }}$, mol m $\mathrm{m}^{-2} \mathrm{~s}^{-1}$ ) that combines evaporation from the wetted fraction of the canopy and transpiration from the dry fraction, as described by Eq. (12). A similar equation applies to shaded leaves. The energy balance given by Eq. (5) does not account for snow in the canopy, so the simulations are restricted to snow-free periods.

These equations are discretized in space and time and are solved in an implicit system of equations for time $n+1$. Ryder et al. (2016) and Chen et al. (2016) describe the solution using a single leaf. Here, the solution is given for separate sunlit and shaded portions of the canopy. In numerical form and with reference to Fig. 1, the scalar conservation equation for temperature is

$$
\begin{aligned}
& \frac{\rho_{\mathrm{m}} \Delta z_{i}}{\Delta t} c_{\mathrm{p}}\left(\theta_{i}^{n+1}-\theta_{i}^{n}\right)-g_{\mathrm{a}, i-1} c_{\mathrm{p}} \theta_{i-1}^{n+1} \\
& +\left(g_{\mathrm{a}, i-1}+g_{\mathrm{a}, i}\right) c_{\mathrm{p}} \theta_{i}^{n+1}-g_{\mathrm{a}, i} c_{\mathrm{p}} \theta_{i+1}^{n+1}= \\
& 2 g_{\mathrm{b}, i} c_{\mathrm{p}}\left(T_{\ell \mathrm{sun}, i}^{n+1}-\theta_{i}^{n+1}\right) \Delta L_{\mathrm{sun}, i} \\
& +2 g_{\mathrm{b}, i} c_{\mathrm{p}}\left(T_{\ell \mathrm{sha}, i}^{n+1}-\theta_{i}^{n+1}\right) \Delta L_{\mathrm{sha}, i}
\end{aligned}
$$

and for water vapor is

$$
\begin{aligned}
& \frac{\rho_{\mathrm{m}} \Delta z_{i}}{\Delta t}\left(q_{i}^{n+1}-q_{i}^{n}\right)-g_{\mathrm{a}, i-1} q_{i-1}^{n+1} \\
& +\left(g_{\mathrm{a}, i-1}+g_{\mathrm{a}, i}\right) q_{i}^{n+1}-g_{\mathrm{a}, i} q_{i+1}^{n+1}= \\
& {\left[q_{\mathrm{sat}}\left(T_{\ell \text { sun }, i}^{n}\right)+s_{i}^{\mathrm{sun}}\left(T_{\ell \text { sun }, i}^{n+1}-T_{\ell \text { sun }, i}^{n}\right)-q_{i}^{n+1}\right]} \\
& g_{\ell \text { sun }, i} \Delta L_{\mathrm{sun}, i}+\left[q_{\mathrm{sat}}\left(T_{\ell \text { sha }, i}^{n}\right)+s_{i}^{\mathrm{sha}}\left(T_{\ell \text { sha }, i}^{n+1}-T_{\ell \text { sha }, i}^{n}\right)\right. \\
& \left.-q_{i}^{n+1}\right] g_{\ell \text { sha }, i} \Delta L_{\mathrm{sha}, i} .
\end{aligned}
$$

The first term on the left-hand side of Eq. (8) is the storage of heat $\left(\mathrm{W} \mathrm{m}^{-2}\right)$ over the time interval $\Delta t(\mathrm{~s})$ in a layer of air with thickness $\Delta z_{i}(\mathrm{~m})$. The next three terms describe the vertical flux divergence from Eq. (3). These use conductance notation in which $g_{\mathrm{a}}$ is an aerodynamic conductance 
( $\left(\mathrm{mol} \mathrm{m}^{-2} \mathrm{~s}^{-1}\right.$ ), as described by Eqs. (24) and (26). $g_{\mathrm{a}, i}$ is the aerodynamic conductance between layer $i$ and $i+1$ above, and $g_{\mathrm{a}, i-1}$ is the similar conductance between layer $i$ and $i-1$ below. The two terms on the right-hand side of Eq. (8) are the vegetation source-sink fluxes of sensible heat for the sunlit and shaded portions of the canopy layer. Equation (9) uses comparable terms for water vapor, with $q_{\text {sat }}\left(T_{\ell \text { sun }}\right)$ and $q_{\text {sat }}\left(T_{\ell \text { sha }}\right)$ linearized as explained below.

The sunlit and shaded temperatures required for Eqs. (8) and (9) are obtained from the energy balance at canopy layer $i$. For the sunlit portion of the canopy

$$
\begin{aligned}
& \frac{c_{\mathrm{L}, i}}{\Delta t}\left(T_{\ell \text { sun }, i}^{n+1}-T_{\ell \text { sun }, i}^{n}\right)= \\
& R_{\mathrm{n} \ell \text { sun }, i}-2 g_{\mathrm{b}, i} c_{\mathrm{p}}\left(T_{\ell \text { sun }, i}^{n+1}-\theta_{i}^{n+1}\right)-\lambda\left[q_{\mathrm{sat}}\left(T_{\ell \text { sun }, i}^{n}\right)\right. \\
& \left.+s_{i}^{\operatorname{sun}}\left(T_{\ell \text { sun }, i}^{n+1}-T_{\ell \text { sun }, i}^{n}\right)-q_{i}^{n+1}\right] g_{\ell \text { sun }, i} .
\end{aligned}
$$

Latent heat flux uses the linear approximation

$q_{\mathrm{sat}}\left(T_{\ell \text { sun }, i}^{n+1}\right)=q_{\mathrm{sat}}\left(T_{\ell \text { sun }, i}^{n}\right)+s_{i}^{\mathrm{sun}}\left(T_{\ell \text { sun }, i}^{n+1}-T_{\ell \text { sun }, i}^{n}\right)$,

with $s_{i}^{\text {sun }}=\mathrm{d} q_{\mathrm{sat}} / \mathrm{d} T$ evaluated at $T_{\ell \text { sun }, i}^{n}$. The leaf boundary layer conductance $\left(g_{\mathrm{b}, i}\right)$ depends on wind speed $\left(u_{i}, \mathrm{~m} \mathrm{~s}^{-1}\right)$ as described by Bonan et al. (2014). The conductance for transpiration is equal to the leaf boundary layer and stomatal conductances acting in series, i.e., $\left(g_{\mathrm{b}, i}^{-1}+g_{\text {sun }, i}^{-1}\right)^{-1}$. Here, it is assumed that $g_{\mathrm{b}, i}$ is the same for heat and water vapor (as in CLM4.5). Stomatal conductance $\left(g_{\text {sun }, i}\right)$ is calculated based on water-use efficiency optimization and plant hydraulics (Bonan et al., 2014). The total conductance $\left(g_{\ell \text { sun, } i}\right)$ combines evaporation from the wetted fraction of the plant material $\left(f_{\mathrm{wet}, i}\right)$ and transpiration from the dry fraction $\left(f_{\mathrm{dry}, i}\right)$, similar to that in CLM4.5 in which

$g_{\ell \text { sun }, i}=\left(\frac{g_{\mathrm{sun}, i} g_{\mathrm{b}, i}}{g_{\mathrm{sun}, i}+g_{\mathrm{b}, i}}\right) f_{\mathrm{dry}, i}+g_{\mathrm{b}, i} f_{\mathrm{wet}, i}$,

with $f_{\text {dry }, i}=f_{\text {green }, i}\left(1-f_{\text {wet }, i}\right)$ so that interception occurs from stems and leaves, but transpiration occurs only from green leaves (denoted by the green leaf fraction $f_{\mathrm{green}, i}$ ). The comparable equation for shaded leaves is

$$
\begin{aligned}
& \frac{c_{\mathrm{L}, i}}{\Delta t}\left(T_{\ell \text { sha }, i}^{n+1}-T_{\ell \text { sha }, i}^{n}\right)= \\
& R_{\mathrm{n} \ell \text { sha }, i}-2 c_{\mathrm{p}}\left(T_{\ell \text { sha }, i}^{n+1}-\theta_{i}^{n+1}\right) g_{\mathrm{b}, i}-\lambda\left[q_{\mathrm{sat}}\left(T_{\ell \text { sha }, i}^{n}\right)\right. \\
& \left.+s_{i}^{\text {sha }}\left(T_{\ell \text { sha }, i}^{n+1}-T_{\ell \text { sha }, i}^{n}\right)-q_{i}^{n+1}\right] g_{\ell \text { sha }, i} .
\end{aligned}
$$

We use post-CLM4.5 changes in intercepted water ( $W$, $\left.\mathrm{kg} \mathrm{m}^{-2}\right)$ and the wet and dry fractions of the canopy ( $f_{\text {wet }}$, $\left.f_{\text {dry }}\right)$ that are included in the next version of the model (CLM5).

At the lowest layer above the ground $(i=1)$, the ground fluxes $H_{0}$ and $E_{0}$ are additional source-sink fluxes, and the ground surface energy balance must be solved to provide the ground temperature $\left(T_{0}^{n+1}, \mathrm{~K}\right)$. This energy balance is

$$
\begin{aligned}
R_{\mathrm{n} 0}= & c_{\mathrm{p}}\left(T_{0}^{n+1}-\theta_{1}^{n+1}\right) g_{\mathrm{a}, 0}+\lambda\left\{h _ { \mathrm { s } 0 } \left[q_{\mathrm{sat}}\left(T_{0}^{n}\right)\right.\right. \\
& \left.\left.+s_{0}\left(T_{0}^{n+1}-T_{0}^{n}\right)\right]-q_{1}^{n+1}\right\} g_{\mathrm{s} 0}+\frac{\kappa_{\text {soil }}}{\Delta z_{\text {soil }}} \\
& \left(T_{0}^{n+1}-T_{\text {soil }}^{n}\right) .
\end{aligned}
$$

The first term on the right-hand side is the sensible heat flux between the ground with temperature $T_{0}$ and the air in the canopy layer immediately above the ground with temperature $\theta_{1} ; g_{\mathrm{a}, 0}$ is the corresponding aerodynamic conductance. The second term is the latent heat flux, with $q_{1}$ the water vapor concentration of the canopy air. In calculating soil evaporation, the surface water vapor concentration is

$$
\begin{aligned}
q_{0}^{n+1} & =h_{\mathrm{s} 0} q_{\mathrm{sat}}\left(T_{0}^{n+1}\right) \\
& =h_{\mathrm{s} 0}\left[q_{\mathrm{sat}}\left(T_{0}^{n}\right)+s_{0}\left(T_{0}^{n+1}-T_{0}^{n}\right)\right],
\end{aligned}
$$

with $s_{0}=\mathrm{d} q_{\mathrm{sat}} / \mathrm{d} T$ evaluated at $T_{0}^{n}$. Evaporation depends on the fractional humidity of the first soil layer $\left(h_{\mathrm{s} 0}\right.$; CLM5). The soil evaporative conductance $\left(g_{\mathrm{s} 0}\right)$ is the total conductance and consists of the aerodynamic conductance $\left(g_{\mathrm{a}, 0}\right)$ and a soil surface conductance to evaporation $\left(g_{\text {soil }}\right.$; CLM5) acting in series. The last term in Eq. (14) is the heat flux to the soil, which depends on the thermal conductivity $\left(\kappa_{\text {soil }}\right)$, thickness $\left(\Delta z_{\text {soil }}\right)$, and temperature $\left(T_{\text {soil }}\right)$ of the first soil layer. Equation (14) does not account for snow on the ground, and the simulations are restricted to snow-free periods.

The numerical solution involves rewriting Eqs. (10) and (13) to obtain expressions for $T_{\ell \operatorname{sun}, i}^{n+1}$ and $T_{\ell \text { sha, } i}^{n+1}$ and substituting these in Eqs. (8) and (9). Equations (14) and (15) provide the necessary expressions for $T_{0}^{n+1}$ and $q_{0}^{n+1}$ at $i=1$. This gives a tridiagonal system of implicit equations with the form

$$
\begin{aligned}
& a_{1, i} \theta_{i-1}^{n+1}+b_{11, i} \theta_{i}^{n+1}+b_{12, i} q_{i}^{n+1}+c_{1, i} \theta_{i+1}^{n+1}=d_{1, i}, \\
& a_{2, i} q_{i-1}^{n+1}+b_{21, i} \theta_{i}^{n+1}+b_{22, i} q_{i}^{n+1}+c_{2, i} q_{i+1}^{n+1}=d_{2, i},
\end{aligned}
$$

in which $a_{1, i}, a_{2, i}, b_{11, i}, b_{21, i}, b_{12, i}, b_{22, i}, c_{1, i}, c_{2, i}, d_{1, i}$, and $d_{2, i}$ are algebraic coefficients (Appendix A1). The system of equations is solved using the method of Richtmyer and Morton (1967, 275-278), as described in Sect. S1 of the Supplement. $\theta_{i}^{n+1}$ and $q_{i}^{n+1}$ are obtained for each level with the boundary conditions $\theta_{\mathrm{ref}}^{n+1}$ and $q_{\mathrm{ref}}^{n+1}$ the temperature and water vapor concentration at some reference height above the canopy. Then, the leaf temperatures and fluxes and ground temperature and fluxes are evaluated. Ryder et al. (2016) used a different, but algebraically equivalent, solution in their model.

The equation set has several dependencies that preclude a fully implicit solution for $\theta_{i}^{n+1}, q_{i}^{n+1}, T_{\ell \text { sun }, i}^{n+1}, T_{\ell \text { sha, } i}^{n+1}$, and 
$T_{0}^{n+1}$. Net radiation depends on leaf and ground temperatures. Ryder et al. (2016) avoided this by specifying longwave emission as an implicit term in the energy balance equation, but there are other complicating factors. Boundary layer conductance is calculated from wind speed, but also air and leaf temperatures (to account for free convection using the Grashof number). The wet and dry fractions of the canopy vary with evaporative flux. Wind speed and aerodynamic conductances depend on the surface layer stability as quantified by the Obukhov length, yet this length scale depends on the surface fluxes. Stomatal conductance requires leaf temperature, air temperature, and water vapor concentration. Further complexity to the canopy flux calculations arises because stomatal conductance is calculated from principles of water transport along the soil-plant-atmosphere continuum such that leaf water potential cannot drop below some threshold (Williams et al., 1996; Bonan et al., 2014). This requires the leaf transpiration flux, which itself depends on stomatal conductance. CLM4.5 has similar dependences in its surface flux calculation and solves the fluxes in a numerical procedure with up to 40 iterations for a single model time step. Instead, we solve the equations using a $5 \mathrm{~min}$ sub-time step to evaluate fluxes over a full model time step (30 min when coupled to an atmospheric model). In the subtime step looping, the current values of wind speed, temperature, water vapor concentration, and canopy water are used to calculate the leaf and aerodynamic conductances needed to update the flux profiles.

\subsection{Plant canopy and roughness sublayer}

The solution to the scalar fluxes and profiles described in the preceding section requires the aerodynamic conductance $\left(g_{\mathrm{a}}\right)$ and also wind speed $(u)$ to calculate leaf boundary layer conductance $\left(g_{\mathrm{b}}\right)$. These are provided by the RSL parameterization. We follow the theory of Harman and Finnigan $(2007,2008)$. In their notation, the coordinate system is defined such that the vertical origin is the top of the canopy and $z$ is the deviation from the canopy top. Here, we retain $z$ as the physical height above the ground, whereby $z-h$ is the deviation from the canopy top. The Harman and Finnigan $(2007,2008)$ parameterization modifies the MOST profiles of $u, \theta$, and $q$ above plant canopies for the RSL and does not require a multilayer canopy (e.g., Harman, 2012), but it was derived by coupling the above-canopy momentum and scalar fluxes with equations for the momentum and scalar balances within a dense, horizontally homogenous canopy. Here, we additionally utilize the within-canopy equations.
Neglecting the RSL, the wind speed profile is described by MOST as

$u(z)=$

$\frac{u_{*}}{k}\left[\ln \left(\frac{z-d}{z_{0}}\right)-\psi_{\mathrm{m}}\left(\frac{z-d}{L_{\mathrm{MO}}}\right)+\psi_{\mathrm{m}}\left(\frac{z_{0}}{L_{\mathrm{MO}}}\right)\right]$,

where $u_{*}$ is friction velocity $\left(\mathrm{m} \mathrm{s}^{-1}\right), z$ is height above the ground $(\mathrm{m}), d$ is displacement height $(\mathrm{m}), z_{0}$ is roughness length $(\mathrm{m})$, and the similarity function $\psi_{\mathrm{m}}$ adjusts the log profile in relation to the Obukhov length $\left(L_{\mathrm{MO}}, \mathrm{m}\right)$. The Harman and Finnigan $(2007,2008)$ RSL parameterization reformulates this as

$$
\begin{aligned}
& u(z)= \\
& \frac{u_{*}}{k}\left[\ln \left(\frac{z-d}{h-d}\right)-\psi_{\mathrm{m}}\left(\frac{z-d}{L_{\mathrm{MO}}}\right)+\psi_{\mathrm{m}}\left(\frac{h-d}{L_{\mathrm{MO}}}\right)\right. \\
& \left.+\hat{\psi}_{\mathrm{m}}\left(\frac{z-d}{L_{\mathrm{MO}}}, \frac{z-d}{l_{\mathrm{m}} / \beta}\right)-\hat{\psi}_{\mathrm{m}}\left(\frac{h-d}{L_{\mathrm{MO}}}, \frac{h-d}{l_{\mathrm{m}} / \beta}\right)+\frac{k}{\beta}\right] .
\end{aligned}
$$

This equation is analogous to the previous equation, but is valid only for wind speed above the canopy at heights $z \geq h$. It rewrites Eq. (18) so that the lower surface is the canopy height $(h, \mathrm{~m})$ rather than the apparent sink for momentum $\left(d+z_{0}\right)$. This eliminates $z_{0}$ but introduces $u(h)$ (the wind speed at the top of the canopy) as a new term, which is specified by $\beta=u_{*} / u(h)$. Equation (19) also introduces $\hat{\psi}_{\mathrm{m}}$, which adjusts the profile to account for canopy-induced physics in the RSL. Whereas $\psi_{\mathrm{m}}$ uses the length scale $L_{\mathrm{MO}}$, $\hat{\psi}_{\mathrm{m}}$ introduces a second length scale $l_{\mathrm{m}} / \beta$. The length scale $l_{\mathrm{m}} / \beta$ is the dominant scale of the shear-driven turbulence generated at or near the canopy top, is equal to $u /(\partial u / \partial z)$ at the top of the canopy, and relates to canopy density. The corresponding equation for temperature above the canopy is

$$
\begin{aligned}
& \theta(z)-\theta(h)= \\
& \frac{\theta_{*}}{k}\left[\ln \left(\frac{z-d}{h-d}\right)-\psi_{\mathrm{c}}\left(\frac{z-d}{L_{\mathrm{MO}}}\right)+\psi_{\mathrm{c}}\left(\frac{h-d}{L_{\mathrm{MO}}}\right)\right. \\
& \left.+\hat{\psi}_{\mathrm{c}}\left(\frac{z-d}{L_{\mathrm{MO}}}, \frac{z-d}{l_{\mathrm{m}} / \beta}\right)-\hat{\psi}_{\mathrm{c}}\left(\frac{h-d}{L_{\mathrm{MO}}}, \frac{h-d}{l_{\mathrm{m}} / \beta}\right)\right],
\end{aligned}
$$

with $\theta_{*}$ a temperature scale $(\mathrm{K})$ and $\psi_{\mathrm{c}}$ and $\hat{\psi}_{\mathrm{c}}$ corresponding functions for scalars. The same equation applies to water vapor, but substituting $q$ and $q_{*}$. The new terms in the profile equations introduced by the RSL theory are $\beta$, the ratio of friction velocity to wind speed at the canopy height; $l_{\mathrm{m}}$, the mixing length $(\mathrm{m})$ in the canopy; and the modified similarity functions $\hat{\psi}_{\mathrm{m}}$ and $\hat{\psi}_{\mathrm{c}}$. Expressions for these are obtained by considering the momentum and scalar balances within a dense, horizontally homogenous canopy and by matching the above- and within-canopy profile equations at the canopy height $h$ (Appendix A2). In addition, the RSL theory provides an equation for $d$, rather than specifying this as an input parameter. Equation (20) also requires $\theta(h)$, the air temperature (K) at the canopy height. Harman and Finnigan (2008) 
provide an equation that relates this to the bulk surface temperature $\left(\theta_{\mathrm{s}}\right)$ for use with a bulk surface parameterization. Here, we treat $\theta(h)$ as a prognostic variable obtained for the top canopy layer as described in the previous section.

With the assumption of a constant mixing length $\left(l_{\mathrm{m}}\right)$ in the canopy, wind speed within the canopy at heights $z \leq h$ follows an exponential decline with greater depth in the canopy in relation to the height $z-h$ normalized by the length scale $l_{\mathrm{m}} / \beta$, with

$u(z)=u(h) \exp \left[\frac{z-h}{l_{\mathrm{m}} / \beta}\right]$

This is the same equation derived by Inoue (1963) and Cionco (1965), but they express the exponential term as $-\eta(1-z / h)$, where $\eta$ is an empirical parameter. Harman and Finnigan $(2007,2008)$ introduced the notation $l_{\mathrm{m}} / \beta$, whereby $\eta / h=\beta / l_{\mathrm{m}}$, so that the exponential decay of wind speed in the canopy relates to the RSL. The wind speed profile matches Eq. (19) at the top of the canopy through $u(h)$. We restrict $u \geq 0.1 \mathrm{~m} \mathrm{~s}^{-1}$ (see Sect. 5 for further details). The corresponding profile for the scalar diffusivity within the canopy is similar to that for wind with

$K_{\mathrm{c}}(z)=K_{\mathrm{c}}(h) \exp \left[\frac{z-h}{l_{\mathrm{m}} / \beta}\right]$.

In the RSL theory of Harman and Finnigan (2008),

$K_{\mathrm{c}}(h)=l_{\mathrm{m}} u_{*} / S c$,

where the Schmidt number $(S c)$ is defined as the ratio of the diffusivities for momentum and scalars at the top of the canopy (Appendix A2). The diffusivity of water vapor is assumed equal to that for heat as in Harman and Finnigan (2008). Equation (21) for $u$ and Eq. (22) for $K_{\mathrm{c}}$ are derived from first-order turbulence closure with constant mixing length in the canopy. They have been used previously to parameterize within-canopy wind and scalar diffusivity in plant canopy models (Shuttleworth and Wallace, 1985; Choudhury and Monteith, 1988), land surface models (Dolman, 1993; Bonan, 1996; Niu and Yang, 2004), and hydrologic models (Mahat et al., 2013; Clark et al., 2015), but without the RSL and with $\eta$ specified as a model parameter.

The aerodynamic conductance for scalars at level $i$ above the canopy $(z>h)$ between heights $z_{i}$ and $z_{i+1}$ is

$$
\begin{aligned}
g_{\mathrm{a}, i}= & \rho_{\mathrm{m}} k u_{*}\left[\ln \left(\frac{z_{i+1}-d}{z_{i}-d}\right)-\psi_{\mathrm{c}}\left(\frac{z_{i+1}-d}{L_{\mathrm{MO}}}\right)\right. \\
& \left.+\psi_{\mathrm{c}}\left(\frac{z_{i}-d}{L_{\mathrm{MO}}}\right)+\hat{\psi}_{\mathrm{c}}\left(z_{i+1}\right)-\hat{\psi}_{\mathrm{c}}\left(z_{i}\right)\right]^{-1},
\end{aligned}
$$

where $\hat{\psi}_{\mathrm{c}}$ is evaluated at $z_{i}$ and $z_{i+1}$. The conductance within the canopy $(z<h)$ consistent with the RSL theory is obtained from Eq. (22) as

$$
\frac{1}{g_{\mathrm{a}, i}}=\frac{1}{\rho_{\mathrm{m}}} \int_{z_{i}}^{z_{i+1}} \frac{\mathrm{d} z}{K_{\mathrm{c}}(z)}
$$

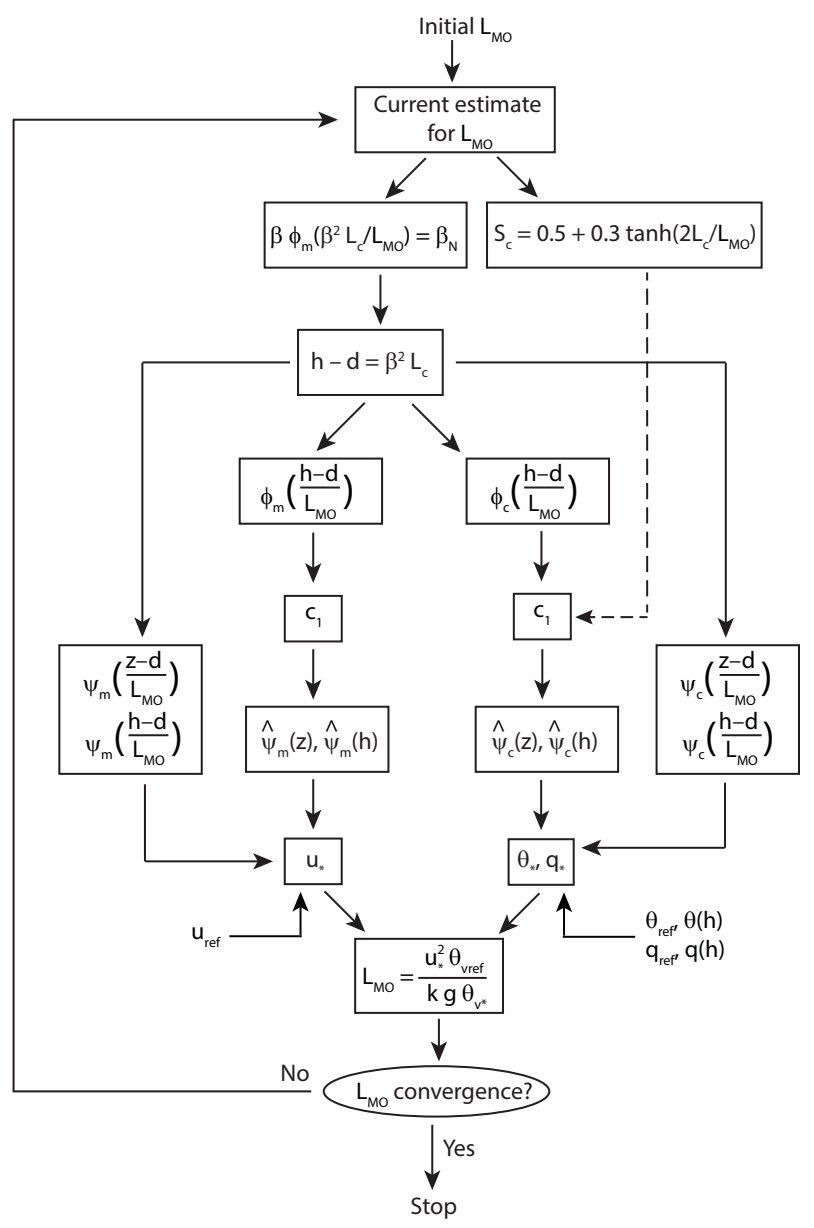

Figure 2. Flow diagram for calculating the Obukhov length $\left(L_{\mathrm{MO}}\right)$.

so that

$$
\begin{aligned}
& \frac{1}{g_{\mathrm{a}, i}}= \\
& \frac{1}{\rho_{\mathrm{m}}} \frac{S c}{\beta u_{*}}\left\{\exp \left[-\frac{\left(z_{i}-h\right)}{l_{\mathrm{m}} / \beta}\right]-\exp \left[-\frac{\left(z_{i+1}-h\right)}{l_{\mathrm{m}} / \beta}\right]\right\} .
\end{aligned}
$$

For the top canopy layer, the conductance is integrated between the heights $z_{i}$ and $h$, and the above-canopy conductance from $h$ to $z_{i+1}$ is additionally included. The conductance immediately above the ground is

$g_{\mathrm{a}, 0}=\rho_{\mathrm{m}} k^{2} u_{1}\left[\ln \left(\frac{z_{1}}{z_{0 \mathrm{~m}, \mathrm{~g}}}\right) \ln \left(\frac{z_{1}}{z_{0 \mathrm{c}, \mathrm{g}}}\right)\right]^{-1}$,

with $z_{0 \mathrm{~m}, \mathrm{~g}}=0.01 \mathrm{~m}$ and $z_{0 \mathrm{c}, \mathrm{g}}=0.1 z_{0 \mathrm{~m}, \mathrm{~g}}$ the roughness lengths of the ground for momentum and scalars, respectively, as in CLM4.5 and assuming neutral stability in this layer. In calculating the conductances, we use the constraint $\rho_{\mathrm{m}} / g_{\mathrm{a}, i} \leq 500 \mathrm{~s} \mathrm{~m}^{-1}$ (see Sect. 5 for further details).

Harman and Finnigan $(2007,2008)$ provide a complete description of the RSL equations and their derivation. Appendix A2 gives the necessary equations as implemented 


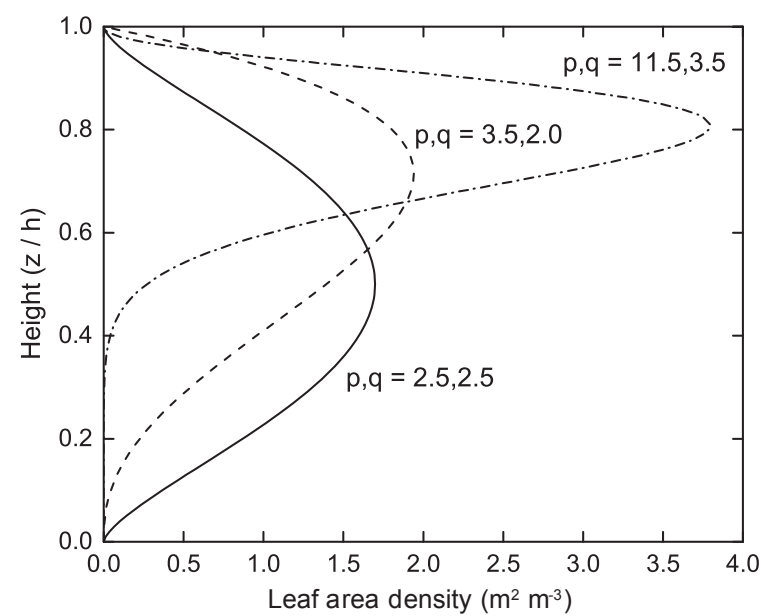

Figure 3. Profiles of leaf area density. Shown are three different canopy profiles for: (i) grass and crop with $p=q=2.5$; (ii) deciduous and spruce trees with $p=3.5$ and $q=2.0$; and (iii) pine trees with $p=11.5$ and $q=3.5$. These profiles are show here with $L_{\mathrm{T}} / h=0.5 \mathrm{~m}^{2} \mathrm{~m}^{-3}$.

herein. Use of the RSL parameterization requires specification of the Monin-Obukhov functions $\psi_{\mathrm{m}}$ and $\psi_{\mathrm{c}}$, the RSL functions $\hat{\psi}_{\mathrm{m}}$ and $\hat{\psi}_{\mathrm{c}}$, and equations for $\beta$ and $S c$. Expressions for $l_{\mathrm{m}}$ and $d$ are obtained from $\beta$. Solution to the RSL parameterization requires an iterative calculation for the Obukhov length $\left(L_{\mathrm{MO}}\right)$ as shown in Fig. 2 and explained further in Appendix A3. The equations as described above apply to dense canopies. Appendix A4 gives a modification for sparse canopies.

\subsection{Plant area density}

Land surface models commonly combine leaf and stem area into a single plant area index to calculate radiative transfer, and CLM4.5 does the same. By using plant area index, big-leaf canopy models assume that woody phytoelements (branches, stems) are randomly interspersed among leaves. Some studies of forest canopies suggest that branches and stems are shaded by foliage and therefore contribute much less to obscuring the sky than if they were randomly dispersed among foliage (Norman and Jarvis, 1974; Kucharik et al., 1998). To allow for shading, we represent plant area density as separate profiles of leaf and stem area. The beta distribution probability density function provides a continuous profile of leaf area density for use with multilayer canopy models, and we use a uniform profile for stem area, whereby

$a(z)=\frac{L_{\mathrm{T}}}{h} \frac{(z / h)^{p-1}(1-z / h)^{q-1}}{B(p, q)}+\frac{S_{\mathrm{T}}}{h}$.

The first term on the right-hand side is the leaf area density with $z / h$ the relative height in the canopy and $L_{\mathrm{T}}$ leaf area index $\left(\mathrm{m}^{2} \mathrm{~m}^{-2}\right)$. The beta function $(B)$ is a normalization constant. The parameters $p$ and $q$ determine the shape of the profile (Fig. 3). Representative values are $p=q=2.5$ for grassland and cropland, $p=3.5$ and $q=2.0$ for deciduous trees and spruce trees, and $p=11.5$ and $q=3.5$ for pine trees (Meyers et al., 1998; Wu et al., 2003). The second term on the right-hand side is the stem area density calculated from the stem area index of the canopy $\left(S_{\mathrm{T}}\right)$. For these simulations, $L_{\mathrm{T}}$ comes from tower data, and $S_{\mathrm{T}}$ is estimated from $L_{\mathrm{T}}$ as in CLM4.5.

\subsection{Leaf heat capacity}

CLM4.5 requires specific leaf area as an input parameter, and we use this to calculate leaf heat capacity (per unit leaf area). Specific leaf area, as used in CLM4.5, is the area of a leaf per unit mass of carbon $\left(\mathrm{m}^{2} \mathrm{~g}^{-1} \mathrm{C}\right)$ and is the inverse of leaf carbon mass per unit area $\left(M_{\mathrm{a}}, \mathrm{g} \mathrm{C} \mathrm{m}^{-2}\right)$. This latter parameter is converted to dry mass assuming the carbon content of dry biomass is $50 \%$ so that the leaf dry mass per unit area is $M_{\mathrm{a}} / f_{\mathrm{c}}$ with $f_{\mathrm{c}}=0.5 \mathrm{~g} \mathrm{Cg}^{-1}$. The leaf heat capacity $\left(c_{\mathrm{L}}\right.$, $\mathrm{J} \mathrm{m}^{-2} \mathrm{~K}^{-1}$ ) is calculated from leaf dry mass per unit area after adjusting for the mass of water, as in Ball et al. (1988) and Blanken et al. (1997). Following Ball et al. (1988), we assume that the specific heat of dry biomass is one-third that of water $\left(c_{\mathrm{dry}}=1.396 \mathrm{~J} \mathrm{~g}^{-1} \mathrm{~K}^{-1}\right)$. Then, with $f_{\mathrm{w}}$ the fraction of fresh biomass that is water, the leaf heat capacity is

$c_{\mathrm{L}}=\frac{M_{\mathrm{a}}}{f_{\mathrm{c}}} c_{\mathrm{dry}}+\frac{M_{\mathrm{a}}}{f_{\mathrm{c}}}\left(\frac{f_{\mathrm{w}}}{1-f_{\mathrm{w}}}\right) c_{\mathrm{wat}}$.

The first term on the right-hand side is the mass of dry biomass multiplied by the specific heat of dry biomass. The second term is the mass of water multiplied by the specific heat of water $\left(c_{\text {wat }}=4.188 \mathrm{~J} \mathrm{~g}^{-1} \mathrm{~K}^{-1}\right)$. We assume that $70 \%$ of fresh biomass is water $\left(f_{\mathrm{w}}=0.7 \mathrm{~g} \mathrm{H}_{2} \mathrm{O} \mathrm{g}^{-1}\right)$. Niinemets (1999) reported a value of $0.66 \mathrm{~g} \mathrm{H}_{2} \mathrm{O} \mathrm{g}^{-1}$ in an analysis of leaves from woody plants. The calculated heat capacity for grasses, crops, and trees is $745-2792 \mathrm{~J} \mathrm{~m}^{-2} \mathrm{~K}^{-1}$ depending on specific leaf area (Table 1). For comparison, Blanken et al. (1997) calculated a heat capacity of $1999 \mathrm{~J} \mathrm{~m}^{-2} \mathrm{~K}^{-1}$ for aspen leaves with a leaf mass per area of $111 \mathrm{~g} \mathrm{~m}^{-2}$ and $f_{\mathrm{w}}=0.8$. Ball et al. (1988) reported a range of $1100-2200 \mathrm{~J} \mathrm{~m}^{-2} \mathrm{~K}^{-1}$ for mangrove leaves spanning a leaf mass per area of $93-189 \mathrm{~g} \mathrm{~m}^{-2}$ with $f_{\mathrm{w}}=0.71$.

\section{Model evaluation}

\subsection{Flux tower data}

We evaluated the canopy model at 12 AmeriFlux sites comprising 81 site years of data using the same protocol of the earlier model development (Bonan et al., 2014). We used the six forests sites previously described in Bonan et al. (2014) and included additional flux data for one forest (US-Dk2), two grassland (US-Dk1, US-Var), and three cropland sites (US-ARM, US-Bo1, US-Ne3) to test the canopy model over 
Table 1. Leaf heat capacity.

\begin{tabular}{lrrr}
\hline Plant functional type & $\begin{array}{r}\text { Specific leaf area } \\
\left(\mathrm{m}^{2} \mathrm{~g}^{-1} \mathrm{C}\right)\end{array}$ & $\begin{array}{r}\text { Leaf mass per area } \\
\left(\mathrm{g} \text { dry mass }{ }^{-2}\right)\end{array}$ & $\begin{array}{r}\text { Heat capacity } \\
\left(\mathrm{J} \mathrm{m}^{-2} \mathrm{~K}^{-1}\right)\end{array}$ \\
\hline Grass, crop & 0.03 & 67 & 745 \\
Deciduous broadleaf tree & 0.03 & 67 & 745 \\
\hline Evergreen needleleaf tree & & & \\
\hline Temperate & 0.01 & 200 & 2234 \\
Boreal & 0.008 & 250 & 2792 \\
\hline
\end{tabular}

Table 2. Site information for the four deciduous broadleaf forest (DBF), three evergreen needleleaf forest (ENF), two grassland (GRA), and three cropland $(\mathrm{CRO})$ flux towers, including mean temperature $(T)$ and precipitation $(P)$ for the simulation month.

\begin{tabular}{|c|c|c|c|c|c|c|c|c|c|}
\hline Site & $\begin{array}{l}\text { Vegetation } \\
\text { type }\end{array}$ & $\begin{array}{l}\text { Lati- } \\
\text { tude }\end{array}$ & $\begin{array}{l}\text { Longi- } \\
\text { tude }\end{array}$ & $\begin{array}{r}T \\
\left({ }^{\circ} \mathrm{C}\right)\end{array}$ & $\begin{array}{r}P \\
(\mathrm{~mm})\end{array}$ & Years & Month & $\begin{array}{l}\text { Leaf area } \\
\text { index }\end{array}$ & $\begin{array}{r}\text { Canopy } \\
\text { height }(m)\end{array}$ \\
\hline US-Dk2 & DBF & 35.97 & -79.10 & 24.7 & 128 & 2004-2008 & July & 6.2 & 25 \\
\hline US-Ha1 & DBF & 42.54 & -72.17 & 20.0 & 103 & 1992-2006 & July & 4.9 & 23 \\
\hline US-MMS & DBF & 39.32 & -86.41 & 24.1 & 112 & 1999-2006 & July & 4.7 & 27 \\
\hline US-UMB & DBF & 45.56 & -84.71 & 20.2 & 63 & 1999-2006 & July & 4.2 & 21 \\
\hline US-Dk3 & ENF & 35.98 & -79.09 & 24.6 & 126 & 2004-2008 & July & 4.7 & 17 \\
\hline US-Ho1 & ENF & 45.20 & -68.74 & 19.3 & 77 & 1996-2004 & July & 4.6 & 20 \\
\hline US-Me2 & ENF & 44.45 & -121.56 & 19.1 & 4 & 2002-2007 & July & 3.8 & 14 \\
\hline US-Dk $1^{b}$ & GRA & 35.97 & -79.09 & 25.1 & 128 & 2004-2008 & July & 1.7 & 0.5 \\
\hline US-Var & GRA & 38.41 & -120.95 & 12.3 & 80 & 2001-2007 & March & 2.4 & 0.6 \\
\hline US-ARM & CRO & 36.61 & -97.49 & 14.7 & 98 & $\begin{array}{l}2003-2004,2006-2007, \\
2009-2010\end{array}$ & April & $2-4$ & 0.5 \\
\hline US-Bo1 & CRO & 40.01 & -88.29 & 22.3 & 53 & 1998-2006 (even) & August & 5.0 & 0.9 \\
\hline US-Ne3 & $\mathrm{CRO}$ & 41.18 & -96.44 & 21.8 & 111 & 2002,2004 & August & 3.7 & 0.9 \\
\hline
\end{tabular}

${ }^{\text {a }}$ Shown is the maximum for the month. Maximum leaf area index for US-ARM varied by year, and shown is the range in monthly maximum across all years. ${ }^{\mathrm{b}} H$ and $u_{*}$ for 2007 and 2008 are excluded.

a range of tall and short canopies, dense and sparse leaf area index, and different climates (Table 2). Tower forcing data (downwelling solar and longwave radiation, air temperature, relative humidity, wind speed, surface pressure, precipitation, and tower height) were from the North American Carbon Program (NACP) site synthesis (Schaefer et al., 2012) as described previously (Bonan et al., 2014), except as noted below for the three Duke tower sites. The model was evaluated using tower observations of net radiation, sensible heat flux, latent heat flux, and friction velocity obtained from the AmeriFlux Level 2 dataset (http://ameriflux.lbl.gov/) and with gross primary production from the NACP site synthesis (Schaefer et al., 2012). The tower forcing and fluxes have a resolution of $30 \mathrm{~min}$ except for four sites (US-Ha1, USMMS, US-UMB, US-Ne3) with 60 min resolution. We limited the simulations to one particular month (with the greatest leaf area) in which soil moisture was prescribed as in Bonan et al. (2014) so as to evaluate the canopy physics parameterizations without confounding effects of seasonal changes in soil water.

Ryu et al. (2008) describe the US-Var grassland located in California. CLM has been previously tested using flux data from the US-Ne3 and US-Bo1 cropland sites (Levis et al., 2012), and we used the same sites here. The US-Ne3 tower site is a rainfed maize (Zea mays) - soybean (Glycine max) rotation located in Nebraska (Verma et al., 2005). We used flux data for soybean, a $C_{3}$ crop (years 2002 and 2004). Kucharik and Twine (2007) give leaf area index, also in the AmeriFlux biological, ancillary, disturbance, and metadata. The same ancillary data show a canopy height of $0.9 \mathrm{~m}$ during August for soybean. The US-Bol site is a maizesoybean rotation located in Illinois (Meyers and Hollinger, 2004; Hollinger et al., 2005). Meyers and Hollinger (2004) give canopy data. We used a leaf area index of $5 \mathrm{~m}^{2} \mathrm{~m}^{-2}$ and canopy height of $0.9 \mathrm{~m}$ for soybean (1998-2006, even years). Flux data for the US-ARM winter wheat site, used to test CLM4.5, provides an additional dataset with which to test the model (Lu et al., 2017).

Stoy et al. (2006) provide site information for the US-Dk2 deciduous broadleaf forest tower site located in the Duke Forest, North Carolina, which was included here to contrast the adjacent evergreen needleleaf forest and grassland sites. The US-Dk1 tower site in the Duke Forest provides an additional test for grassland (Novick et al., 2004; Stoy et al., 
Table 3. Major differences between CLM4.5 and ML + RSL.

\begin{tabular}{|c|c|c|}
\hline Feature & CLM4.5 & $\mathrm{ML}+\mathrm{RSL}$ \\
\hline Canopy & $\begin{array}{l}\text { Dual source: vegetation (sunlit/shaded big-leaf) } \\
\text { and soil }\end{array}$ & $\begin{array}{l}\text { Multilayer; sunlit and shaded leaf fluxes at each } \\
\text { level; scalar profiles }(u, \theta, q) \text { based on conser- } \\
\text { vation equations }\end{array}$ \\
\hline Plant area index & Big leaf & $\begin{array}{l}\text { Vertical profile uses beta distribution probabil- } \\
\text { ity density function for leaves and uniform pro- } \\
\text { file for stems }\end{array}$ \\
\hline Stomatal conductance & $g_{\mathrm{s}}=g_{0}+g_{1} h_{\mathrm{s}} A_{\mathrm{n}} / c_{\mathrm{s}}$ & $\begin{array}{l}\Delta A_{\mathrm{n}} / \Delta E_{\ell}=\iota \text { with } \psi_{\ell}>\psi_{\ell \min } \text {; Bonan et } \\
\text { al. (2014) }\end{array}$ \\
\hline $\begin{array}{l}\text { Relative leaf nitrogen profile } \\
f_{i}=\exp \left[-K_{\mathrm{n}} \sum \Delta L_{j}\right]\end{array}$ & $K_{\mathrm{n}}=0.3$ & $\begin{array}{l}K_{\mathrm{n}}=\exp \left(0.00963 V_{\mathrm{c}_{\max }}-2.43\right) \\
\text { Bonan et al. }(2014)\end{array}$ \\
\hline Storage & - & $\begin{array}{l}\text { Plant: } c_{\mathrm{L}}\left(\Delta T_{\ell} / \Delta t\right) \\
\text { Air: } \rho_{\mathrm{m}} c_{\mathrm{p}} \Delta z(\Delta \theta / \Delta t) \\
\text { Air: } \rho_{\mathrm{m}} \Delta z(\Delta q / \Delta t)\end{array}$ \\
\hline Above-canopy turbulence & MOST & RSL \\
\hline Within-canopy turbulence & $\begin{array}{l}\text { Understory wind speed equals } u_{*} ; \text { aerodynamic } \\
\text { conductance based on } u_{*} \text { and understory Ri. }\end{array}$ & $\begin{array}{l}u(z)=u(h) \exp \left[(z-h) \beta / l_{\mathrm{m}}\right] \\
K_{\mathrm{c}}(z)=K_{\mathrm{c}}(h) \exp \left[(z-h) \beta / l_{\mathrm{m}}\right]\end{array}$ \\
\hline
\end{tabular}

Table 4. Summary of simulation changes to the turbulence parameterization and leaf biophysics.

\begin{tabular}{|c|c|c|c|c|c|c|}
\hline \multirow[b]{2}{*}{ Simulation } & \multicolumn{2}{|c|}{ Turbulence } & \multicolumn{4}{|c|}{ Biophysical } \\
\hline & $\theta, q$ & $u, g_{\mathrm{a}}$ & $g_{\mathrm{s}}$ & $K_{\mathrm{n}}$ & Plant area density & $c_{\mathrm{L}}$ \\
\hline CLM4.5 & CLM4.5 & CLM4.5 & CLM4.5 & CLM4.5 & - & - \\
\hline $\mathrm{m} 0$ & Well-mixed & - & CLM4.5 & CLM4.5 & $\left(L_{\mathrm{T}}+S_{\mathrm{T}}\right) / h$ & - \\
\hline $\mathrm{m} 1$ & Eqs. (16) and (17) & $\begin{array}{l}z>h: \text { CLM4.5 } \\
z<h: \text { Eqs. }(21) \text { and (26) } \\
\eta=3\end{array}$ & CLM4.5 & CLM4.5 & $\mathrm{m} 0$ & - \\
\hline b1 & $\mathrm{m} 1$ & $\mathrm{~m} 1$ & $\begin{array}{l}\text { Bonan et } \\
\text { al. }(2014)\end{array}$ & CLM4.5 & $\mathrm{m} 0$ & - \\
\hline b2 & $\mathrm{m} 1$ & $\mathrm{~m} 1$ & b1 & $\begin{array}{l}\text { Bonan et } \\
\text { al. }(2014)\end{array}$ & $\mathrm{m} 0$ & - \\
\hline b3 & $\mathrm{m} 1$ & $\mathrm{~m} 1$ & b1 & $\mathrm{b} 2$ & Eq. (28) & - \\
\hline $\mathrm{b} 4$ & $\mathrm{~m} 1$ & $\mathrm{~m} 1$ & b1 & $\mathrm{b} 2$ & b3 & Eq. (29) \\
\hline $\mathrm{r} 1$ & $\mathrm{~m} 1$ & $\begin{array}{l}z>h: \text { Eqs. (19) and (24) } \\
z<h: \text { Eqs. (21) and (26), } \\
\eta=3\end{array}$ & b1 & $\mathrm{b} 2$ & b3 & $\mathrm{b} 4$ \\
\hline $\mathrm{r} 2$ & $\mathrm{~m} 1$ & $\mathrm{r} 1 ; \eta$ replaced by $l_{\mathrm{m}} / \beta$ & b1 & b2 & b3 & b4 \\
\hline
\end{tabular}

2006). Tower forcing and flux data for 2004-2008 were as in Burakowski et al. (2018).

\subsection{Model simulations}

We performed several model simulations to compare CLM4.5 with the RSL enabled multilayer canopy. CLM4.5 and the multilayer canopy differ in several ways (Table 3). To facilitate comparison and to isolate specific model differences, we devised a series of simulations to incrementally test parameterization changes (Table 4). The simulations discussed herein are as follows.

1. CLM4.5 - Simulations with CLM4.5 using tower meteorology and site data for leaf area index, stem area index, and canopy height.

2. m0 - This uses the multilayer canopy, but configured to be similar to CLM4.5 for leaf biophysics as described in Table 3. Stomatal conductance is calculated as in CLM4.5. Leaf nitrogen declines exponentially with greater cumulative plant area index from the 
Table 5. Average Taylor skill score for the ML + RSL (first number) and CLM4.5 (second number) simulations. Skill scores greater than those of CLM4.5 are highlighted in bold. GPP: gross primary production.

\begin{tabular}{lrrrrrr}
\hline Site & $R_{\mathrm{n}}$ & $H$ & $\lambda E$ & $u_{*}$ & $T_{\text {rad }}$ & GPP \\
\hline Forest & & & & & & \\
\hline US-Ha1 & $\mathbf{0 . 9 8} / 0.98$ & $\mathbf{0 . 8 9} / 0.85$ & $\mathbf{0 . 9 4} / 0.92$ & $\mathbf{0 . 9 1} / 0.82$ & - & $\mathbf{0 . 8 3} / 0.80$ \\
US-MMS & $\mathbf{1 . 0 0 / 0 . 9 9}$ & $0.44 / 0.47$ & $\mathbf{0 . 8 8} / 0.87$ & $\mathbf{0 . 8 4} / 0.78$ & $\mathbf{0 . 8 9} / 0.81$ & $0.70 / 0.70$ \\
US-UMB & $0.99 / 0.99$ & $\mathbf{0 . 9 0} / 0.84$ & $\mathbf{0 . 9 2} / 0.88$ & $\mathbf{0 . 9 3} / 0.89$ & $\mathbf{0 . 9 2} / 0.75$ & $\mathbf{0 . 8 1} / 0.73$ \\
US-Dk2 & $\mathbf{0 . 9 8} / 0.98$ & $\mathbf{0 . 5 3} / 0.52$ & $0.93 / 0.93$ & $\mathbf{0 . 8 6} / 0.82$ & $\mathbf{0 . 7 5} / 0.75$ & - \\
US-Dk3 & $\mathbf{0 . 9 9 / 0 . 9 9}$ & $\mathbf{0 . 8 5} / 0.85$ & $0.94 / 0.94$ & $0.81 / 0.82$ & $\mathbf{0 . 8 3} / 0.79$ & - \\
US-Ho1 & $0.96 / 0.97$ & $0.93 / 0.94$ & $0.91 / 0.93$ & $\mathbf{0 . 9 2} / 0.86$ & - & $0.86 / 0.87$ \\
US-Me2 & $\mathbf{1 . 0 0} / 1.00$ & $\mathbf{0 . 9 0} / 0.79$ & $\mathbf{0 . 8 9} / 0.64$ & $\mathbf{0 . 8 8} / 0.84$ & $\mathbf{0 . 9 4} / 0.78$ & $\mathbf{0 . 9 1} / 0.57$ \\
\hline Herbaceous & & & & & & \\
\hline US-Dk1 & $0.99 / 0.99$ & $\mathbf{0 . 8 9} / 0.87$ & $0.90 / 0.90$ & $0.73 / 0.82$ & $\mathbf{0 . 9 8} / 0.95$ & - \\
US-Var & $0.95 / 0.96$ & $\mathbf{0 . 7 2} / 0.59$ & $\mathbf{0 . 9 5} / 0.95$ & $\mathbf{0 . 8 1} / 0.79$ & $0.98 / 0.98$ & $\mathbf{0 . 8 9} / 0.79$ \\
US-Bo1 & $0.99 / 0.99$ & $\mathbf{0 . 7 5} / 0.61$ & $\mathbf{0 . 9 6} / 0.94$ & $\mathbf{0 . 9 4} / 0.94$ & $\mathbf{0 . 9 0} / 0.85$ & - \\
US-Ne3 & $\mathbf{1 . 0 0} / 1.00$ & $\mathbf{0 . 4 8} / 0.35$ & $\mathbf{0 . 8 5} / 0.77$ & $\mathbf{0 . 9 8} / 0.96$ & $\mathbf{0 . 9 4} / 0.86$ & $\mathbf{0 . 7 8} / 0.59$ \\
US-ARM & $0.96 / 0.97$ & $\mathbf{0 . 9 3} / 0.88$ & $0.91 / 0.94$ & $0.95 / 0.95$ & $\mathbf{0 . 9 8} / 0.97$ & - \\
\hline
\end{tabular}

canopy top with the decay coefficient $K_{\mathrm{n}}=0.3$ as in CLM4.5. The nitrogen profile determines the photosynthetic capacity at each layer so that leaves in the upper canopy have greater maximum photosynthetic rates than leaves in the lower canopy. In addition, leaf and stem area are comingled in CLM4.5, and there is no heat storage in plant biomass. These features are replicated by having a uniform plant area density profile and by setting leaf heat capacity to a small, nonzero number. This simulation excludes a turbulence parameterization so that air temperature, water vapor concentration, and wind speed in the canopy are equal to the reference height forcing. Juang et al. (2008) referred to this as the well-mixed assumption. In this configuration, the fluxes of sensible and latent heat above the canopy are the sum of the source-sink fluxes in the canopy, and friction velocity is not calculated. This is the baseline model configuration.

3. $\mathrm{m} 1$ - As in $\mathrm{m} 0$, but introducing a turbulence closure in the absence of the RSL. Equations (16) and (17) are used to calculate $\theta$ and $q$. The CLM4.5 MOST parameterization is used to calculate $u$ and $g_{\mathrm{a}}$ above the canopy. Within the canopy, the mixing length model with exponential profiles for $u$ and $g_{\mathrm{a}}$ as in Eqs. (21) and (26) is used, but with $\eta=3$, which is a representative value found in many observational studies of wind speed in plant canopies (Thom, 1975; Cionco, 1978; Brutsaert, 1982).

The multilayer canopy model has several changes to leaf biophysics compared with CLM4.5. These differences are individually examined in the simulations.
4. b1 - As in $\mathrm{m} 1$, but with stomatal conductance calculated using water-use efficiency and plant hydraulics as in Bonan et al. (2014).

5. b2 - As in b1, but with $K_{\mathrm{n}}$ dependent on photosynthetic capacity $\left(V_{c_{\max }}\right)$ as in Bonan et al. (2014).

6. b3 - As in b2, but with plant area density calculated from Eq. (28).

7. b4 - As in b3, but with leaf heat capacity from Eq. (29). This represents the full suite of parameterization changes prior to inclusion of the RSL. We also refer to this simulation as ML-RSL.

The final two simulations examine the RSL.

8. $\mathrm{r} 1$ - As in $\mathrm{b} 4$, but with the RSL parameterization used to calculate $u$ and $g_{\mathrm{a}}$ above the canopy using Eqs. (19) and (24). In this configuration, the CLM4.5 MOST parameterization is replaced by the RSL parameterization for above-canopy profiles, but $\eta=3$ for within canopy profiles.

9. $\mathrm{r} 2$ - As in $\mathrm{r} 1$, but $u$ and $g_{\mathrm{a}}$ in the canopy are calculated from the RSL parameterization using $l_{\mathrm{m}} / \beta$ rather than $\eta=3$. This is the full ML + RSL configuration, and comparison with ML-RSL shows the effects of including the RSL parameterization.

Simulations were evaluated in terms of net radiation, sensible heat flux, latent heat flux, gross primary production, friction velocity, and radiative temperature. Radiative temperature for both the observations and simulations was evaluated from the upward longwave flux using an emissivity of 1 . The simulations were assessed in terms of root mean 
(a)

CLM4.5
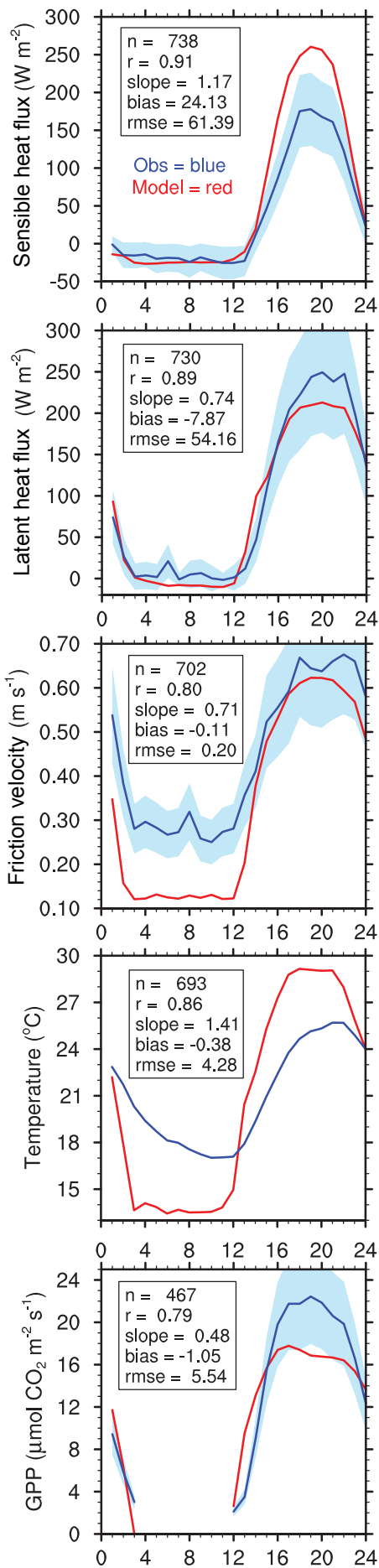

(b) $\quad$ ML-RSL
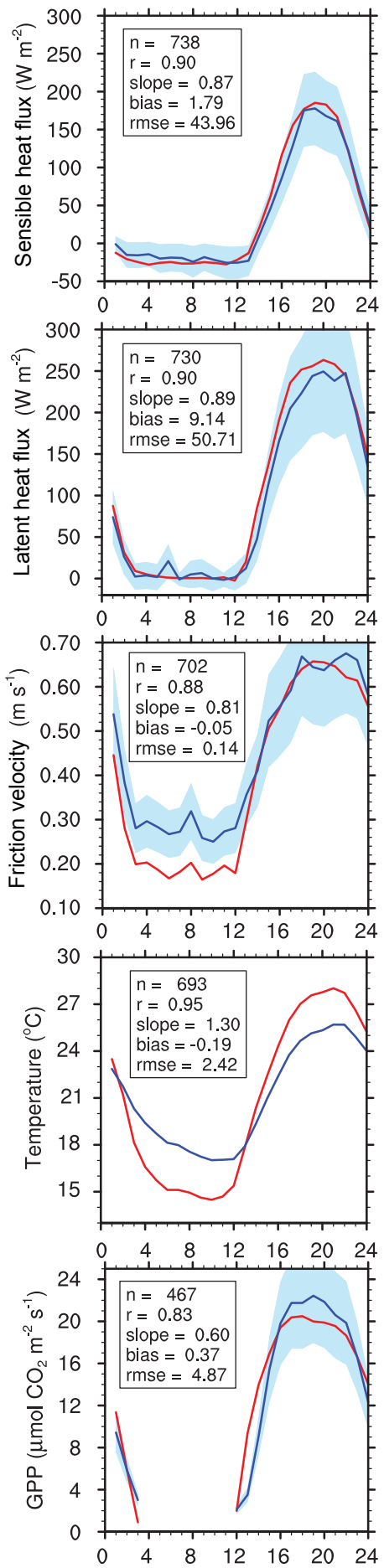

(c) $\quad \mathrm{ML}+\mathrm{RSL}$
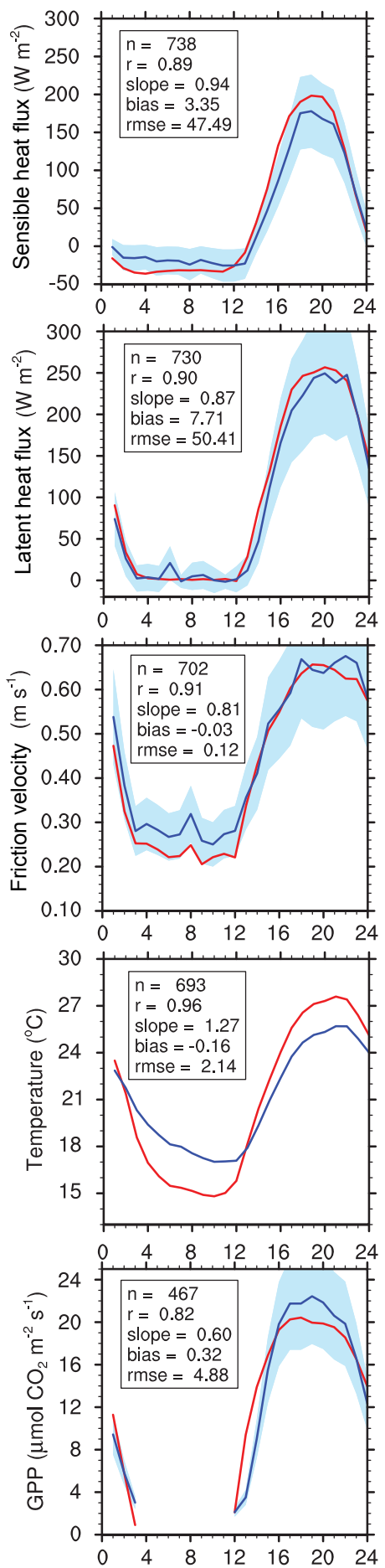

Figure 4. Simulations for US-UMB (July 2006). Shown are the average diurnal cycle (GMT) of sensible heat flux, latent heat flux, friction velocity, radiative temperature, and gross primary production (GPP) for the observations (blue) and models (red). The shading denotes \pm 1 standard deviation of the random flux error (Richardson et al., 2006, 2012) for $H$ and $\lambda E$ and $\pm 20 \%$ of the mean for GPP and $u_{*}$. Statistics show sample size $(n)$, correlation coefficient $(r)$, slope of the regression line, mean bias, and root mean square error (rmse) between the model and observations. (a) CLM4.5; (b) ML-RSL; (c) ML + RSL. 

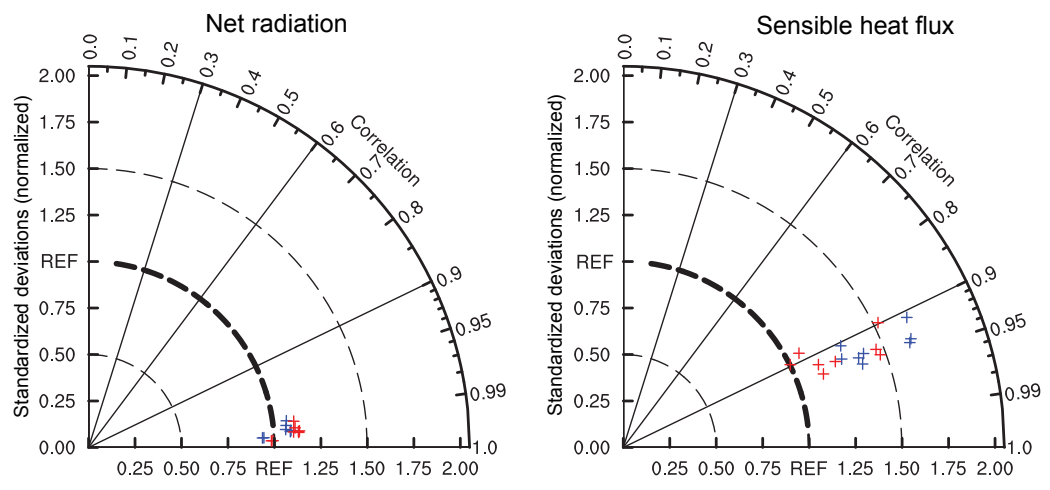

Latent heat flux

Friction velocity
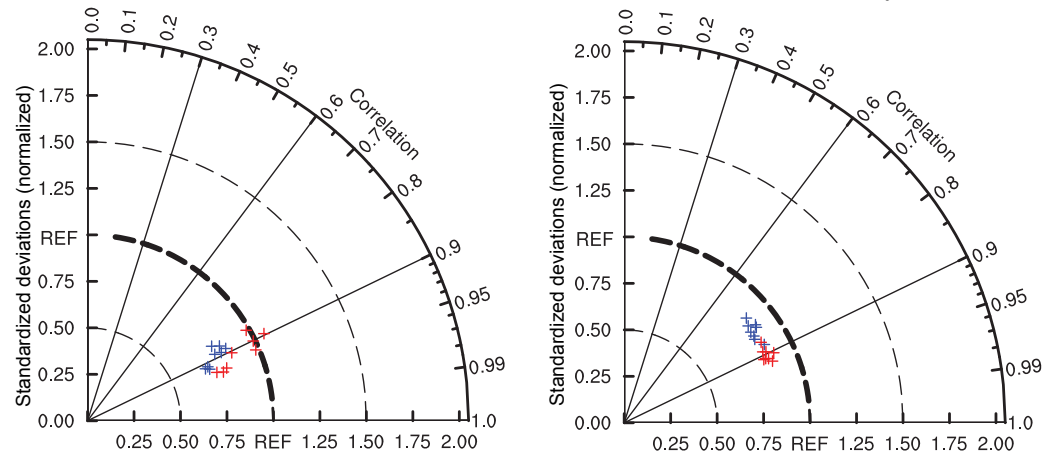

Radiative temperature
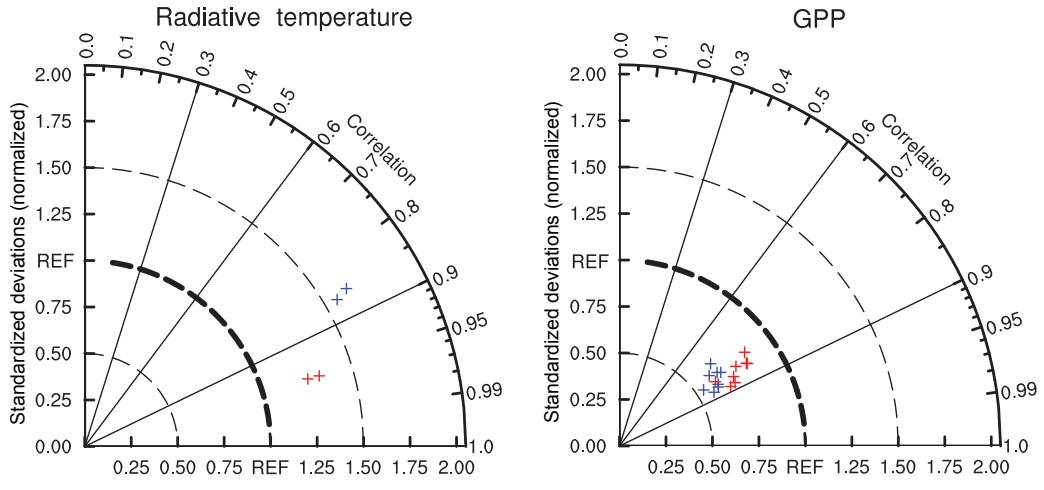

CLM4.5

$\mathrm{ML}+\mathrm{RSL}$

Figure 5. Taylor diagram of net radiation, sensible heat flux, latent heat flux, friction velocity, radiative temperature, and gross primary production (GPP) for US-UMB. Data points are for the years 1999-2006 for CLM4.5 (blue) and ML + RSL (red). Simulations are evaluated with the normalized standard deviation relative to the observations (given by the radial distance of a data point from the origin) and the correlation with the observations (given by the azimuthal position). The thick dashed reference line (REF) indicates a normalized standard deviation equal to 1 . Model improvement is seen by radial closeness to the REF line and azimuth closeness to the horizontal axis (correlation coefficient equal to 1$)$.

square error (RMSE) for each of the 81 site years. We additionally assessed model performance using Taylor diagrams and the corresponding skill score (Taylor, 2001) as in Bonan et al. (2014). Taylor diagrams quantify the degree of similarity between the observed and simulated time series of a particular variable in terms of the correlation coefficient $(r)$ and the standard deviation of the model data relative to that of the observations $(\hat{\sigma})$. The Taylor skill score combines these two measures into a single metric of model performance with a value of 1 when $r=1$ and $\hat{\sigma}=1$.

\section{Results}

\subsection{Model evaluation}

The ML + RSL simulation has better skill compared with CLM4.5 at most sites and for most variables (Table 5). Of the seven forest sites, net radiation $\left(R_{\mathrm{n}}\right)$ is improved at five sites, sensible heat flux $(H)$ at five sites, latent heat flux $(\lambda E)$ at four sites, friction velocity $\left(u_{*}\right)$ at six sites, radiative temperature $\left(T_{\mathrm{rad}}\right)$ at the five sites with data, and gross primary 

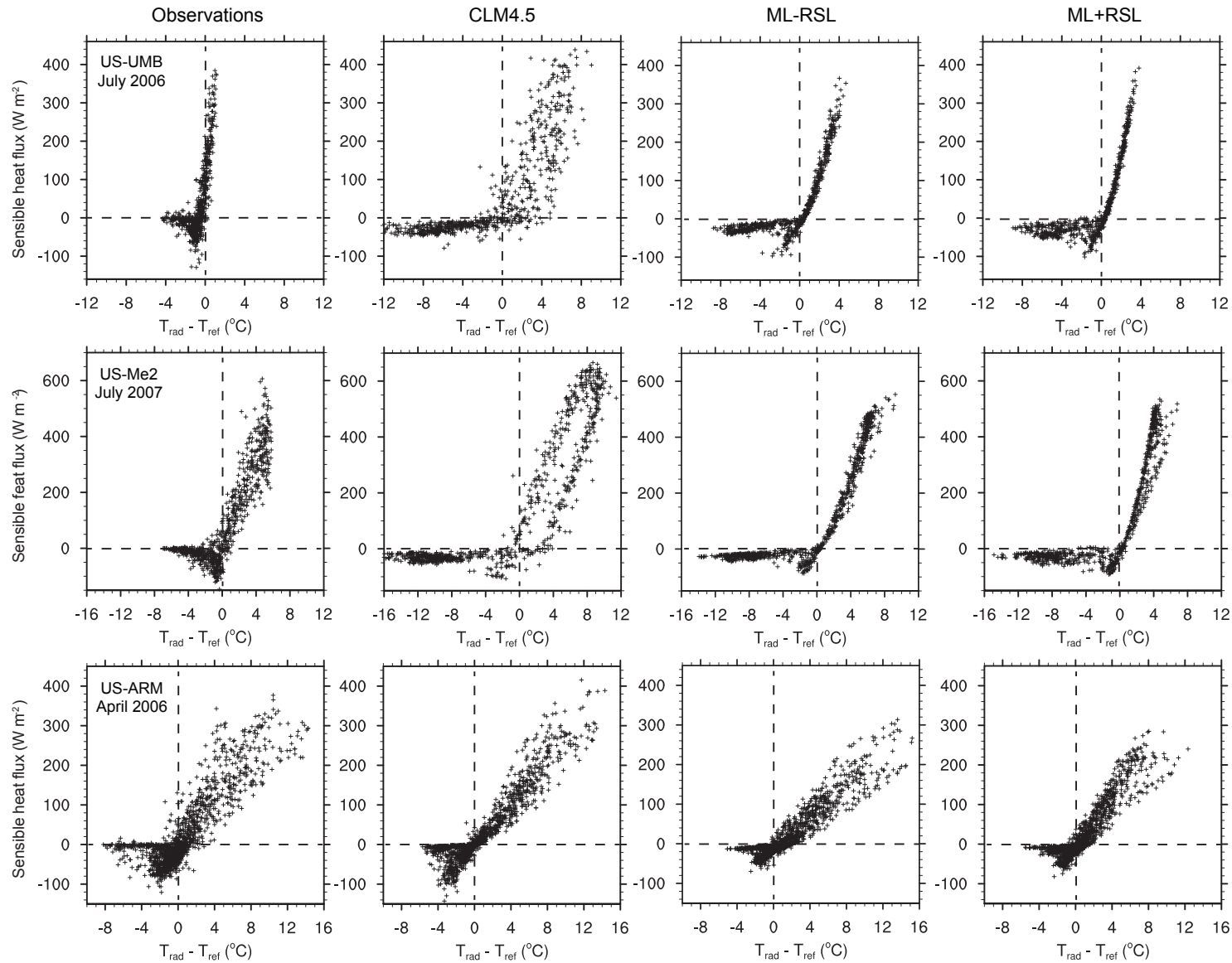

Figure 6. Sensible heat flux in relation to the temperature difference $T_{\mathrm{rad}}-T_{\text {ref }}$ for US-UMB (July 2006), US-Me2 (July 2007), and US-ARM (April 2006). Shown are the observations (left column) and model results for CLM4.5, ML-RSL, and ML + RSL.

production at three of the five sites with data. $H$ is improved at all five herbaceous sites, $\lambda E$ at three sites, $u_{*}$ at three sites, $T_{\text {rad }}$ at four sites, and gross primary production at the two sites with data. $R_{\mathrm{n}}$ generally is unchanged at the herbaceous sites.

Simulations for US-UMB illustrate these improvements for the forest sites, where the influence of the RSL is greatest. For July 2006, CLM4.5 overestimates midday $H$ and underestimates midday gross primary production (Fig. 4). Midday latent heat flux is biased low, but within the measurement error. $u_{*}$ is underestimated at night, and $T_{\text {rad }}$ has a larger diurnal range with colder temperatures at night and warmer temperatures during the day compared with the observations. ML $+\mathrm{RSL}$ improves the simulation. Midday $H$ decreases and gross primary production increases, nighttime $u_{*}$ increases, and the diurnal range of $T_{\mathrm{rad}}$ decreases. Taylor diagrams for all years (1999-2006; Fig. 5) show improved $H, \lambda E$, and gross primary production (in terms of the variance of the modeled fluxes relative to the observations), $u_{*}$ (in terms of correlation with the observations), and $T_{\text {rad }}$ (both variance and correlation). Similar improvements are seen at the other forest sites.
Figure 6 shows the relationship between $H$ and the temperature difference between the surface and reference height $\left(T_{\text {rad }}-T_{\text {ref }}\right)$ for two forest sites (US-UMB and US-Me2) and one crop site (US-ARM). These sites were chosen because the RMSE of the model (ML + RSL) is low for $H$ and $T_{\text {rad }}$. The observations show a positive correlation between $T_{\text {rad }}-T_{\text {ref }}$ and $H$ beginning at about $-2{ }^{\circ} \mathrm{C}$. CLM4.5 and ML + RSL capture this relationship, but the slope at the forest sites is smaller for CLM4.5 than for ML + RSL and the CLM4.5 data have more scatter. For stable conditions $(H<0)$, CLM4.5 shows a slight linear increase in sensible heat transfer to the surface (US-UMB) or is nearly invariant (US-Me2) as $T_{\text {rad }}$ becomes progressively colder than $T_{\text {ref. }}$. ML + RSL better captures the observations, particularly the more negative $H$ as $T_{\text {rad }}-T_{\text {ref }}$ approaches zero. CLM4.5 also has a wider range of temperatures compared with the observations and ML + RSL at the forest sites. The primary effect of the RSL is to reduce high daytime temperatures and to increase sensible heat transfer to the surface at night. Model differences are less at US-ARM. 


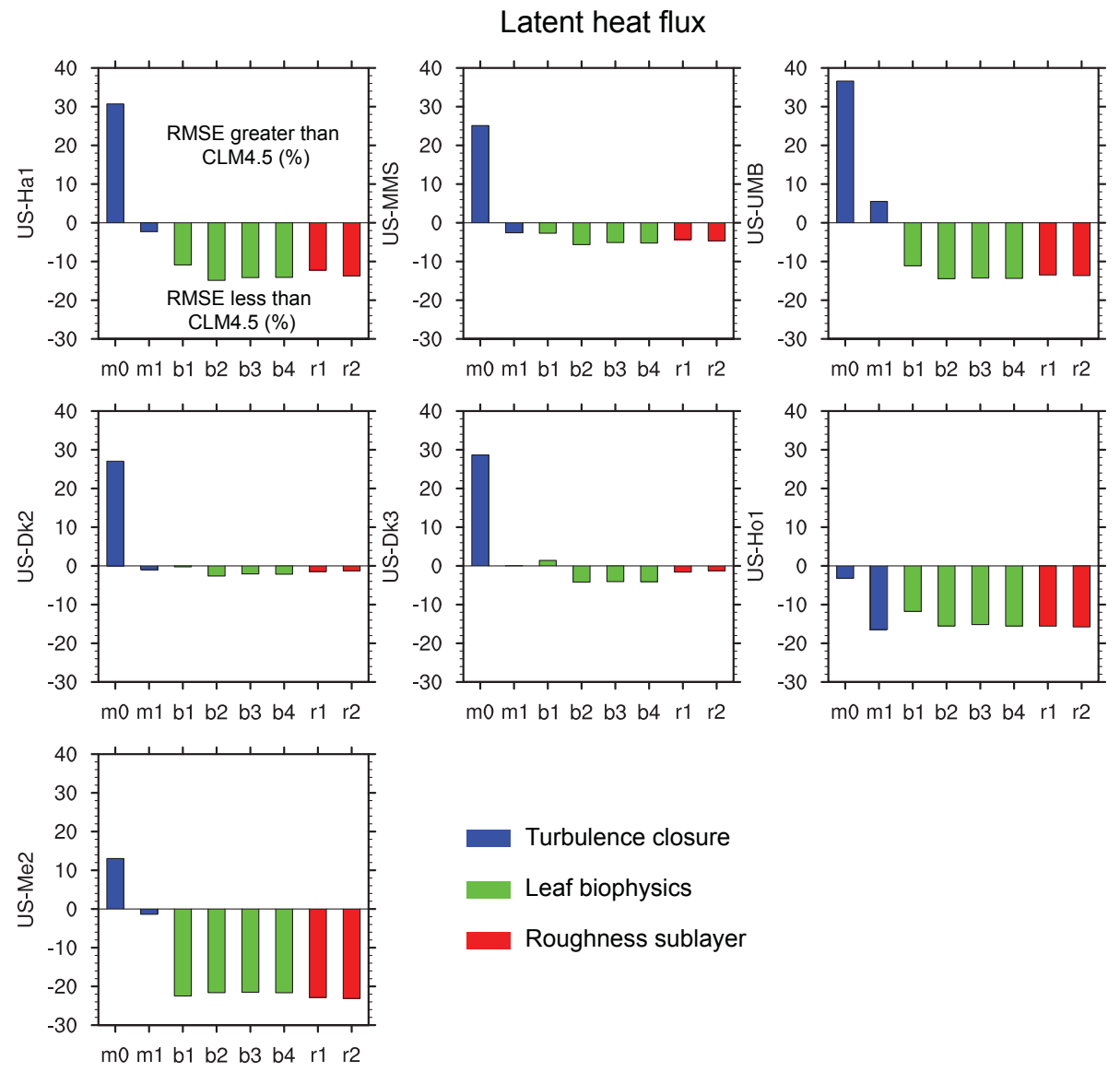

Figure 7. Root mean square error (RMSE) for latent heat flux for the eight simulations m0-r2. RMSE for each simulation is given as a percentage of the RMSE for CLM4.5 and averaged across all years at each of the seven forest sites. A negative value shows a reduction in RMSE relative to CLM4.5 and indicates model improvement. Changes in RMSE between simulations show the effect of sequentially including new model parameterizations as described in Table 4.

\subsection{Effect of specific parameterizations}

Comparisons of ML-RSL and ML + RSL for US-UMB (July 2006) show improvements in the multilayer canopy even without the RSL parameterization (Fig. 4). ML-RSL reduces midday $H$, increases midday $\lambda E$ and gross primary production, and reduces the diurnal range of $T_{\text {rad }}$. The nighttime bias in $u_{*}$ also decreases. Inclusion of the RSL (ML + RSL) further improves $u_{*}$ and $T_{\text {rad }}$, but slightly degrades $H$ by increasing the daytime peak.

Comparison of the suite of simulations ( $\mathrm{m} 0$ to $\mathrm{r} 2$; Table 4 ) for forest sites highlights the effect of specific parameterization changes on model performance. The $\mathrm{m} 0$ simulation without a turbulence closure has a high RMSE compared with CLM4.5 for $\lambda E$ (Fig. 7) and $H$ (Fig. 8). Inclusion of a turbulence closure (above-canopy, CLM4.5 MOST; withincanopy, mixing length model) in $\mathrm{m} 1$ substantially reduces RMSE compared with $\mathrm{m} 0$ at all sites. The $\mathrm{m} 1$ RMSE for $\lambda E$ is reduced compared with CLM4.5 at five of the seven sites and for $H$ at four sites. The leaf biophysical simula- tions (b1-b4) reduce $\lambda E$ RMSE compared with $\mathrm{m} 1$ at six sites (US-Ho1 is the exception), and the RMSE also decreases compared with CLM4.5 (Fig. 7). Among b1-b4, the biggest effect on $\lambda E$ RMSE occurs from stomatal conductance and nitrogen profiles (b1 and b2). The RSL parameterization ( $\mathrm{r} 1$ and $\mathrm{r} 2$ ) has relatively little additional effect on RMSE. The leaf biophysical simulations (b1-b4) have a similar effect to reduce RMSE for $H$ compared with 1 , and RMSE decreases compared with CLM4.5 (Fig. 8). Inclusion of the RSL ( $\mathrm{r} 1$ and $\mathrm{r} 2$ ) degrades $H$ in terms of RMSE. Whereas the b4 simulation without the RSL parameterization decreases RMSE compared with CLM4.5, this reduction in RMSE is lessened in $\mathrm{r} 1$ and $\mathrm{r} 2$. The RMSE for $u_{*}$ in $\mathrm{m} 1$ decreases compared with CLM4.5 at all sites (Fig. 9). The leaf biophysics simulations have little effect on RMSE, but the RSL simulations ( $\mathrm{r} 1$ and $\mathrm{r} 2$ ) further reduce RMSE. The $\mathrm{m} 0$ simulation without a turbulence closure has a substantially lower RMSE for $T_{\text {rad }}$ compared with the other simulations (Fig. 10). This is seen in an improved simulation of the diurnal temperature range, with warmer nighttime minimum and 

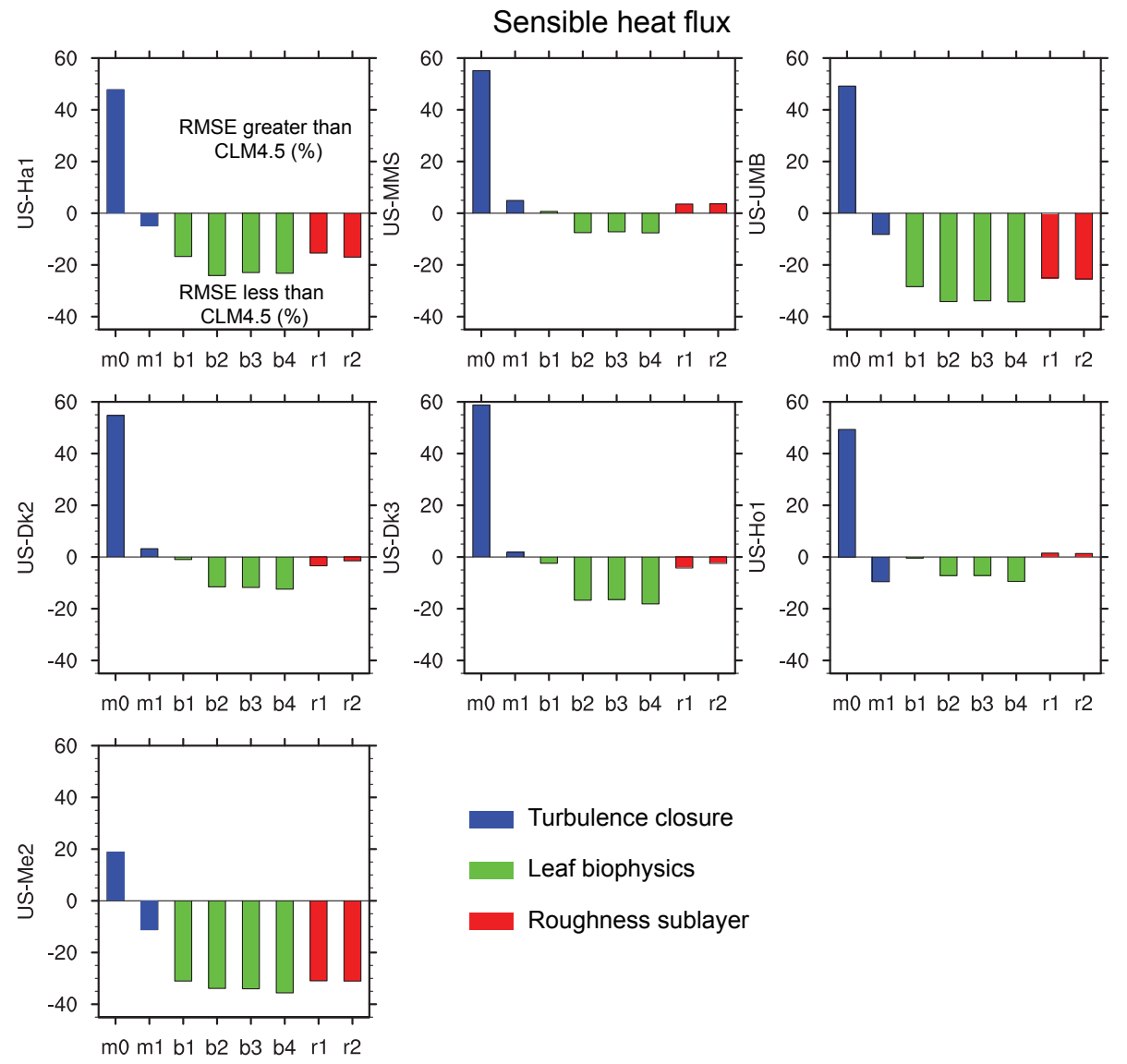

Figure 8. As in Fig. 7, but for sensible heat flux.

cooler daytime maximum temperatures compared with the other simulations (not shown). The $\mathrm{m} 1$ simulation increases RMSE, but RMSE is still reduced compared with CLM4.5 at the five sites with data. The leaf biophysical simulations (b1b4) have little effect on $T_{\text {rad }}$, but the RSL simulations reduce RMSE, more so for $\mathrm{r} 1$ than $\mathrm{r}$.

\subsection{Canopy profiles}

Leaf temperature profiles are consistent with the changes in $T_{\text {rad }}$, as shown in Fig. 11 for US-UMB. The m0 simulation has the coolest daytime and warmest nighttime leaf temperatures. Inclusion of a turbulence closure ( $\mathrm{m} 1)$ warms daytime temperatures and cools nighttime temperatures. The leaf biophysics (b4) reduces the $\mathrm{m} 1$ temperature changes, and the RSL simulations ( $\mathrm{r} 1$ and $\mathrm{r} 2$ ) further reduce the changes.

Wind speed and temperature profiles simulated with the RSL parameterization are noticeably different compared with MOST profiles, as shown in Fig. 12 for US-UMB. At midday, wind speed in the upper canopy is markedly lower than for MOST, but whereas wind speed goes to zero with MOST, the RSL wind speed remains finite. Midday MOST air temperature in the canopy increases monotonically to a maximum of $28.5^{\circ} \mathrm{C}$, but the RSL produces a more complex profile with a temperature maximum of about $26.5^{\circ} \mathrm{C}$ in the mid-canopy and lower temperatures near the ground. During the night, the upper canopy cools to a temperature of about $15^{\circ} \mathrm{C}$, but temperatures in the lower canopy remain warm. The other forest sites show similar profiles.

\section{Discussion}

The multilayer canopy with the RSL (ML + RSL) improves the simulation of surface fluxes compared to CLM4.5 at most forest and herbaceous sites (Table 5). In terms of $\lambda E$, the turbulence closure using the CLM4.5 MOST above the canopy and a mixing length model in the canopy (with $\eta=3$ ) substantially reduces RMSE compared to the well-mixed assumption in which the canopy has the same temperature, water vapor concentration, and wind speed as the reference height $(\mathrm{m} 0, \mathrm{~m} 1$; Fig. 7). A similar result is seen for $H$ (Fig. 8). This finding is consistent with Juang et al. (2008), who showed that first-order turbulence closure improves simulations in a multilayer canopy compared with the wellmixed assumption.

Additional improvement in $\lambda E$ comes from the leaf biophysics (particularly stomatal conductance and photosyn- 

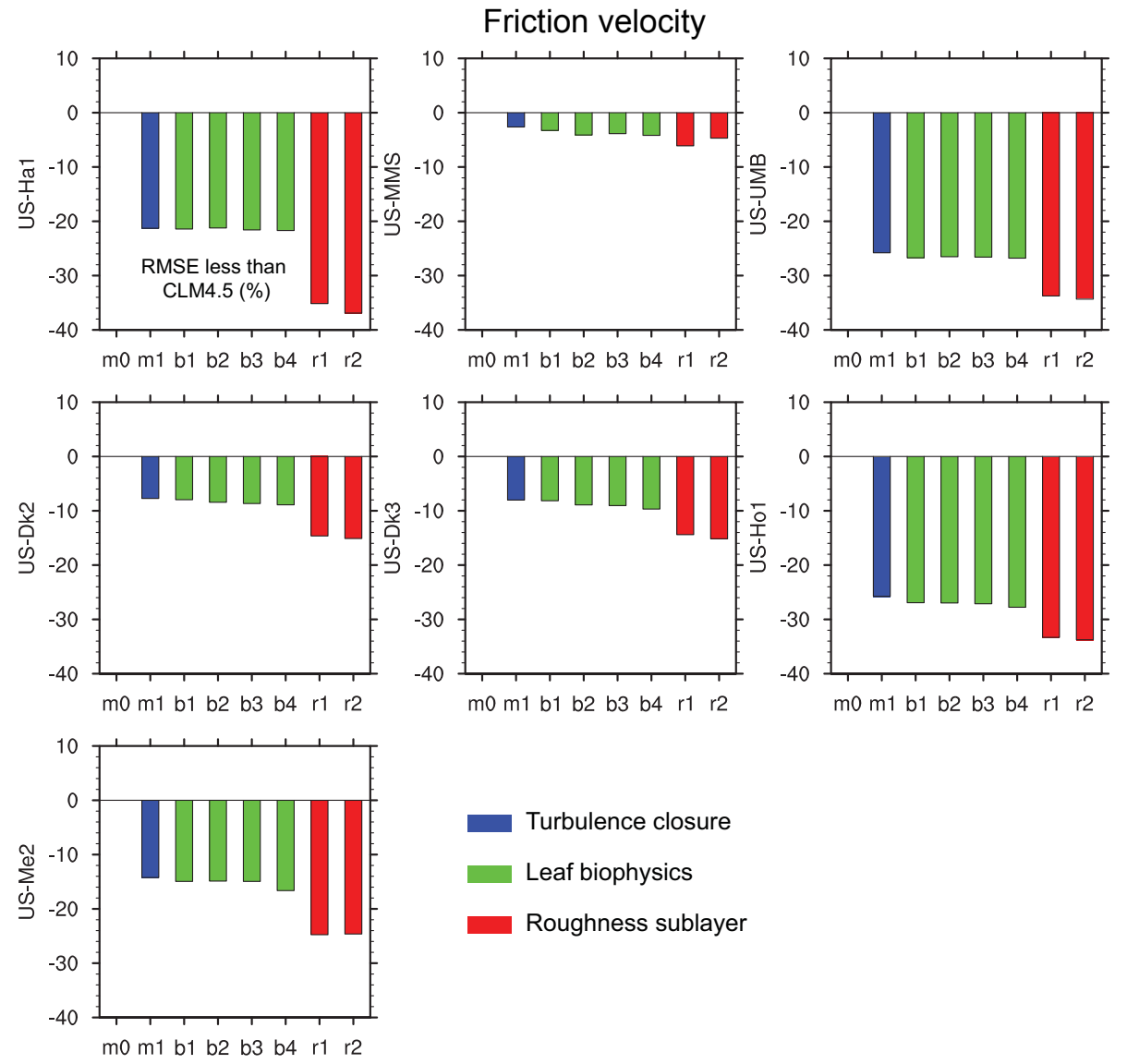

Figure 9. As in Fig. 7, but for friction velocity.

thetic capacity) (b1, b2; Fig. 7). This is consistent with Bonan et al. (2014), who previously showed improvements arising from the multilayer canopy, stomatal conductance, and photosynthetic capacity at the forest sites. Differences between the CLM4.5 and ML + RSL stomatal models likely reflect differences in parameters (slope $g_{1}$ for CLM4.5; marginal water-use efficiency $\iota$ for ML + RSL) rather than model structure (Franks et al., 2017). Further differences arise from the plant hydraulics (Bonan et al., 2014). The RSL has comparatively little effect on $\lambda E$ (r1, r2; Fig. 7). $H$ is similarly improved by the leaf biophysics, but is degraded by the RSL (Fig. 8) because of an increase in the peak midday flux. Harman (2012) also found that the RSL has negligible effect on $\lambda E$ because this flux is dominated by stomatal conductance, but increases the peak $H$.

The influence of the RSL is evident in the improved relationship between $H$ and the surface-air temperature difference $\left(T_{\text {rad }}-T_{\text {ref }}\right)$ at forest sites (Fig. 6). In CLM4.5, a larger temperature difference is needed to produce the same positive heat flux to the atmosphere compared with the observations. With the RSL, a smaller temperature difference gives the same sensible heat flux, comparable to the observations. This is expected from the RSL theory because of the larger aerodynamic conductance. Additional improvement, as expected from the RSL theory, is seen during moderately stable periods, which in turn reduces surface cooling. Similar such improvement is not seen at the shorter crop site (US-ARM).

The influence of the RSL is also evident in nighttime $u_{*}$ (Fig. 4). Substantial reduction in RMSE is seen in the $\mathrm{m} 1$ simulation (Fig. 9), which closely mimics CLM4.5 in terms of leaf biophysics and use of MOST above the canopy. The different numerical methods used between the multilayer canopy and CLM4.5 to solve for canopy temperature, surface fluxes, and the Obukhov length may explain the poor CLM4.5 simulations. The RSL parameterization further improves $u_{*}$ (r1, r2; Fig. 9), primarily by increasing $u_{*}$ at night as expected due to shear-driven turbulence induced by the canopy dominating during night compared with day.

Another outcome of the RSL is seen in $T_{\text {rad }}$ and leaf temperature. The lowest RMSE occurs with the well-mixed approximation (m0; Fig. 10), which also produces the coolest daytime and warmest nighttime leaf temperatures $(\mathrm{m} 0$; Fig. 11). Adding a turbulence closure (m1) substantially warms daytime leaf temperatures and cools nighttime temperatures, which degrades the $T_{\text {rad }}$ RMSE. The RSL (r1, r2) decreases the daytime temperatures and warms the nighttime 

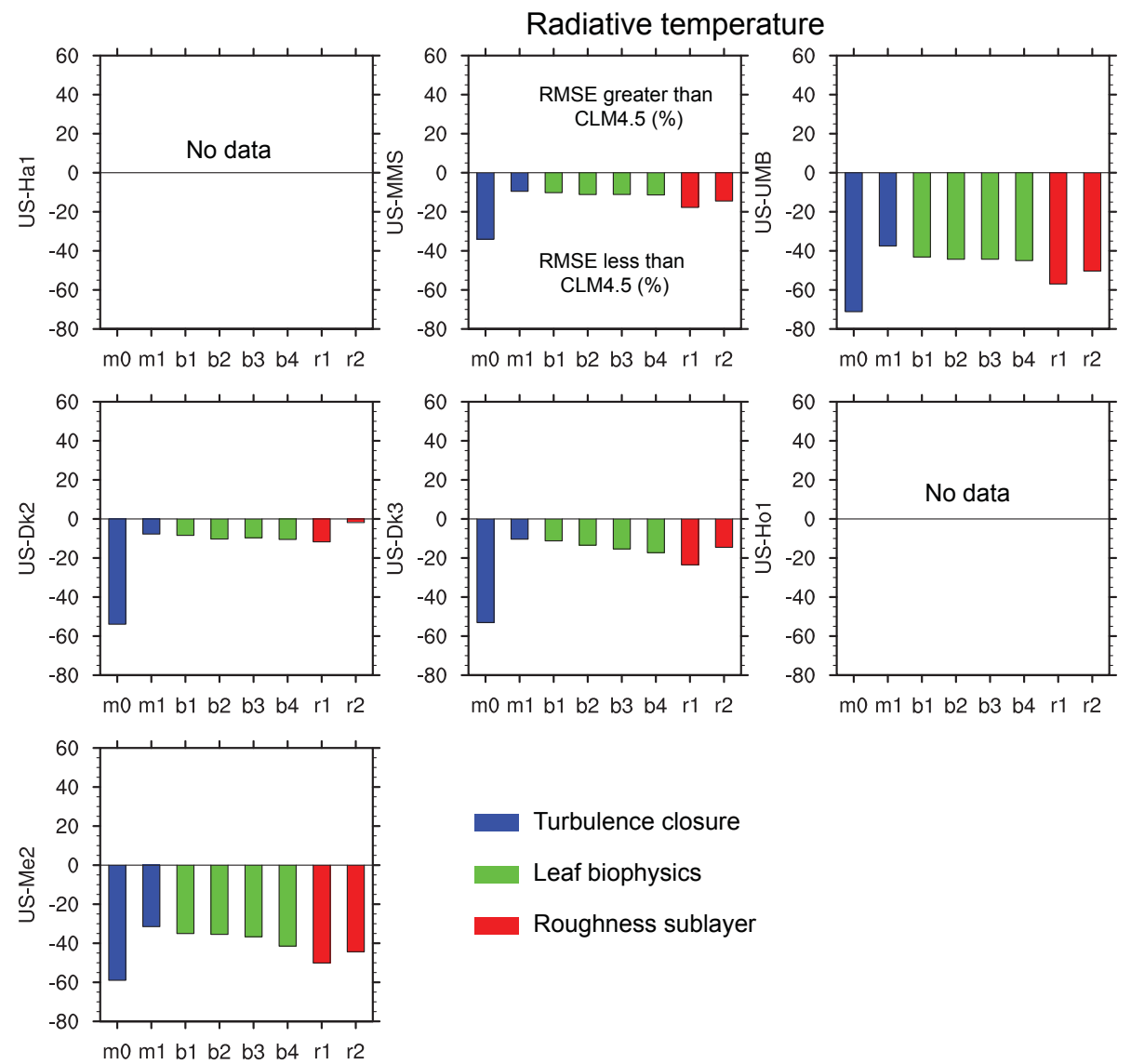

Roughness sublayer

Figure 10. As in Fig. 7, but for radiative temperature.
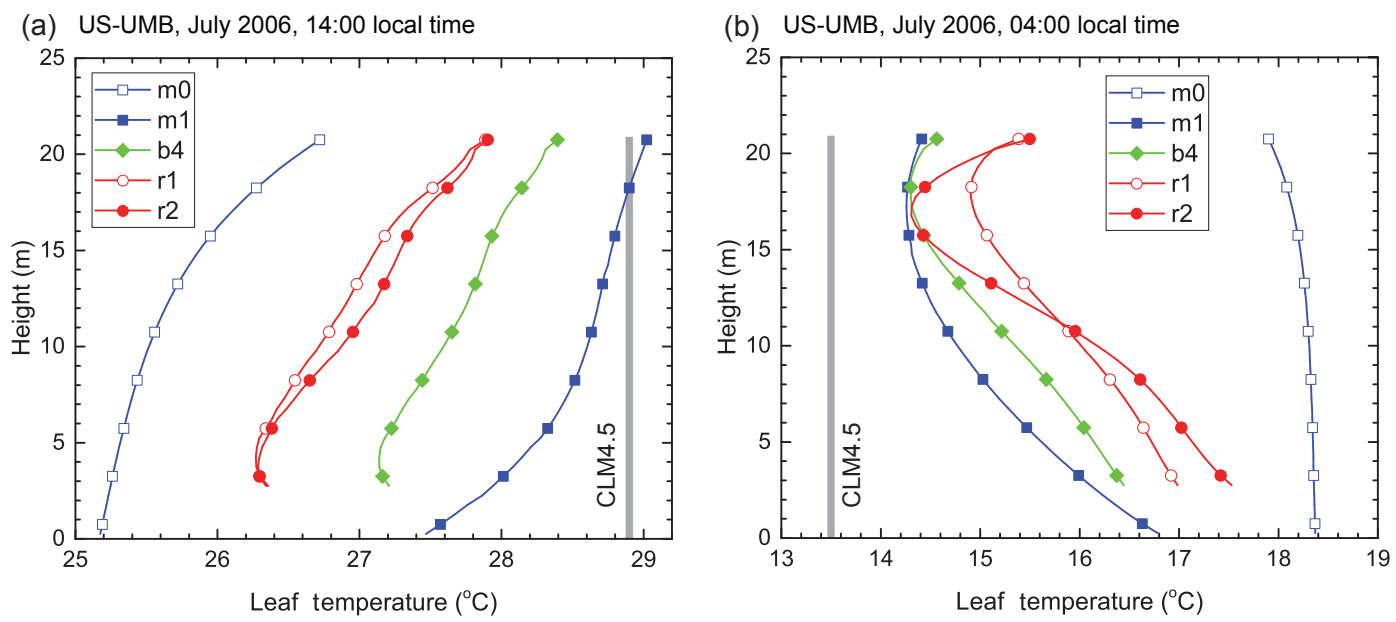

Figure 11. Profiles of leaf temperature for US-UMB averaged for the month of July 2006 at 14:00 local time (a) and 04:00 local time (b). Temperature is averaged for sunlit and shaded leaves at each level in the canopy. Shown are the m0, m1, b4 (ML-RSL), r1, and r2 (ML + RSL) simulations. The CLM4.5 canopy temperature is shown as a thick gray line, but is not vertically resolved.

temperatures, which improves the RMSE. Leaf temperatures are cooler during the day and warmer at night compared with CLM4.5. Overall, the diurnal temperature range improves in the ML + RSL simulation compared to that from CLM4.5, seen in both the nighttime minimum and the daytime maximum of $T_{\text {rad }}$ (Fig. 4). This latter improvement is particularly important given the use of radiometric land surface temper- 

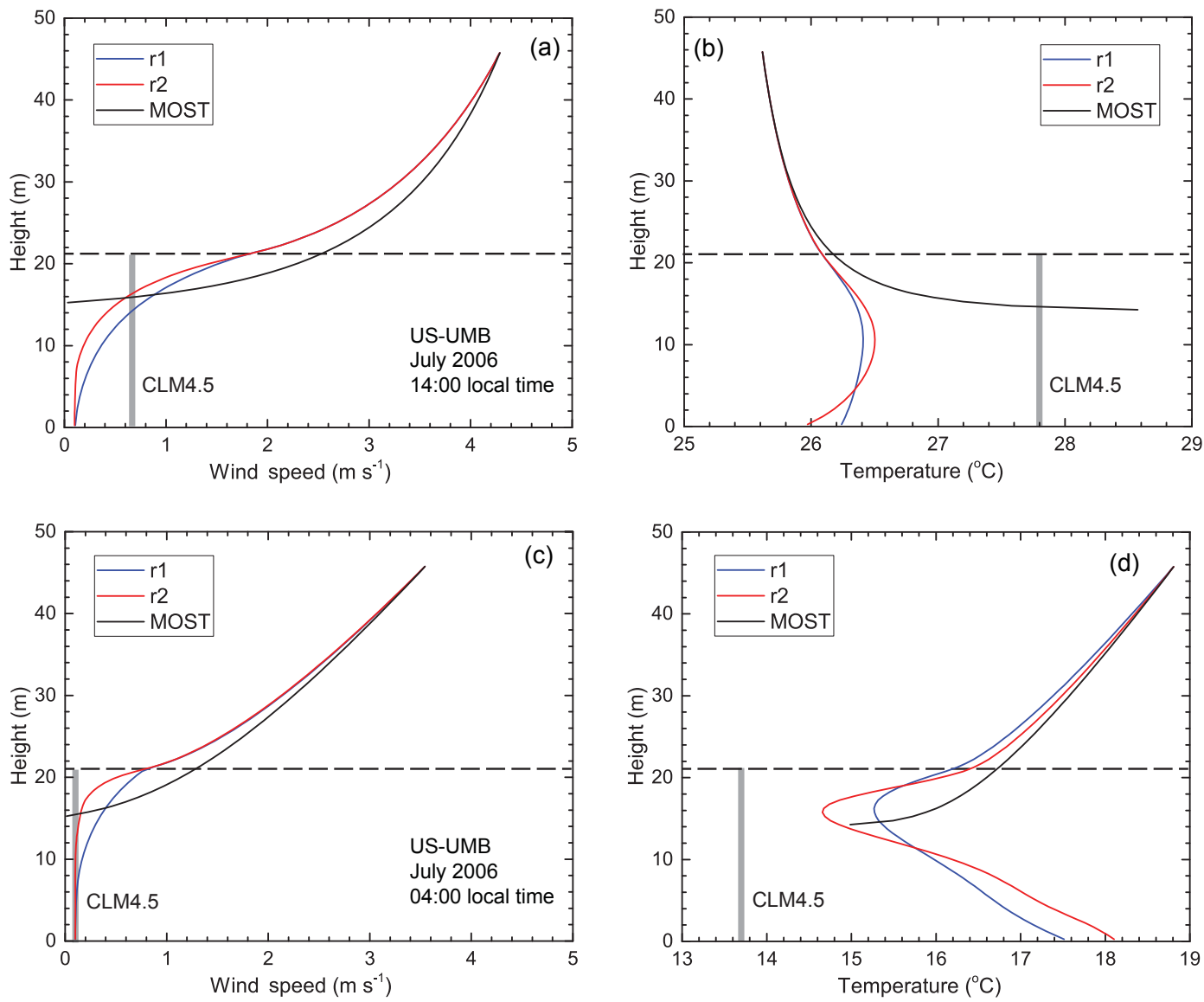

Figure 12. Profiles of wind speed and air temperature for US-UMB (July 2006) at 14:00 local time (a, b) and 04:00 local time (c, d). Shown are the $\mathrm{r} 1$ and $\mathrm{r} 2$ simulations averaged for the month. The dashed line denotes the canopy height. The CLM4.5 canopy wind speed and air temperature are shown as a thick gray line, but are not vertically resolved. Also shown are the profiles obtained using MOST extrapolated to the surface. This extrapolation is for the $\mathrm{r} 2$ simulation using MOST flux-profile relationships and with roughness length and displacement height specified as in CLM4.5.

ature as an indicator of the climate impacts of land cover change (Alkama and Cescatti, 2016).

The simulation of wind and temperature profiles is a key outcome of the multilayer canopy and RSL. During the day, CLM4.5 simulates a warmer canopy air space than those for ML + RSL simulation (Fig. 12). Air temperature obtained from MOST increases monotonically towards the bulk surface, whereas the ML + RSL simulation produces a more complex vertical profile with a maximum located in the upper canopy and cooler temperatures in the lower canopy. Geiger (1927) first described such profiles, seen also in some studies (Jarvis and McNaughton, 1986; Pyles et al., 2000; Staudt et al., 2011). The simulated nighttime temperatures are warmer than CLM4.5. Temperature profiles have a minimum in the upper canopy, above which temperature increases with height. However, temperatures increase in the lower canopy. Nighttime temperatures in a walnut orchard show a minimum in the upper canopy arising from radiative cooling, but the temperature profile in the lower canopy is more uniform than seen in Fig. 12 (Patton et al., 2011). En- hanced diffusivity resulting from convective instability in the canopy makes the temperature profile more uniform in the Patton et al. (2011) observations; this process is lacking in the RSL parameterization. Ryder et al. (2016) and Chen et al. (2016) noted the difficulty in modeling nighttime temperature profiles in forests and introduced in ORCHIDEECAN an empirical scaling factor to $K_{\mathrm{c}}$ that varies between day and night. The results of the present study, too, suggest that turbulent mixing in conditions in which the stratification within and above the canopy differ in sign needs additional consideration. The importance of within-canopy temperature gradients is seen in forest canopies. The microclimatic influence of dense forest canopies buffers the impact of macroclimatic warming on understory plants (De Frenne et al., 2013), and the vertical climatic gradients in tropical rainforests are steeper than elevation or latitudinal gradients (Scheffers et al., 2013).

Various ad hoc changes have been introduced into the next version of the Community Land Model (CLM5) to correct the deficiencies in $u_{*}$ and $T_{\text {rad }}$. In particular, the Monin- 
Obukhov stability parameter has been constrained in stable conditions so that $(z-d) / L_{\mathrm{MO}} \leq 0.5$. This change increases nighttime $u_{*}$, increases sensible heat transfer to the surface at night, and increases nighttime $T_{\text {rad }}$ (not shown). In contrast, the ML + RSL simulation reduces these same biases, but resulting from a clear theoretical basis describing canopyinduced physics.

The canopy model encapsulates conservation equations for $\theta$ and $q$, the energy balance for the sunlit and shaded canopy, and the ground surface energy balance. The various terms in Eqs. (16) and (17), the governing equations, are easily derived from flux equations and relate to the leaf $\left(g_{\mathrm{b}}, g_{\ell \text { sun }}, g_{\ell \text { sha }}\right)$ and aerodynamic $\left(g_{\mathrm{a}}\right)$ conductances, leaf and canopy air storage terms $\left(c_{\mathrm{L}}, \rho_{\mathrm{m}} \Delta z / \Delta t\right)$, plant area index and the sunlit fraction $\left(\Delta L, f_{\text {sun }}\right)$, net radiation $\left(R_{\mathrm{n} \ell \text { sun }}\right.$, $\left.R_{\mathrm{n} \ell \text { sha }}\right)$, and soil surface $\left(R_{\mathrm{n} 0}, h_{\mathrm{s} 0}, g_{\mathrm{s} 0}, \kappa_{\text {soil }}, T_{\text {soil }}\right)$. These are all terms that need to be defined in land surface models (except for the storage terms which are commonly neglected), and so the only new term introduced into the flux equations is leaf heat capacity, but that is obtained from the leaf mass per area, which is a required parameter in CLM4.5.

The Harman and Finnigan $(2007,2008)$ RSL parameterization provides the necessary aerodynamic conductances and wind speed. It produces a comparable representation of surface-atmosphere exchange of heat, water, and carbon, including within-canopy exchange, to those based on Lagrangian dynamics (e.g., McNaughton and van den Hurk, 1995) and localized near-field theory (e.g., Raupach, 1989; Raupach et al., 1997; Siqueira et al., 2003; Ryder et al., 2016; Chen et al., 2016). Lagrangian representations have the advantage in that they retain closer fidelity to the underlying dynamics governing exchange. In contrast, however, the RSL formulation provides linked representations for both momentum and (passive) scalar exchange. This coupling, impossible with Lagrangian formulations as there is no locally conserved equivalent quantity to scalar concentration for momentum, reduces the degrees of freedom involved. The RSL's linked formulation also facilitates the propagation of knowledge about the transport of one quantity onto the transport of all other quantities considered. Unlike Lagrangian formulations, the RSL formulation also naturally asymptotes towards the standard surface layer representations as required, e.g., with increasing height above ground or for short canopies.

Furthermore, the components of the RSL formulation are far easier to observe than those in the Lagrangian representations. In particular, the vertical profile of the Lagrangian timescale $\left(T_{\mathrm{L}}\right)$, critical to the localized near-field formulation, is extremely difficult to determine from observations or higher-order numerical simulations. Most understanding around $T_{\mathrm{L}}$ is indirect, heuristic, or tied to an inverted model (Massman and Weil, 1999; Haverd et al., 2009). Finally, it is worth noting that the RSL formulation is derived from the scales of the coherent and dominant turbulent structures and directly incorporates canopy architecture (Raupach et al., 1996; Finnigan et al., 2009), thereby permitting future adap- tation of the formulation to advances in our understanding of the structure and role of turbulence, e.g., to variation with canopy architecture, landscape heterogeneity, or in low wind conditions. Far greater effort would be required to update the parameterizations of the components in the Lagrangian representations to advances in the understanding of turbulence.

The Harman and Finnigan $(2007,2008)$ RSL parameterization eliminates a priori specification of roughness length and displacement height, but introduces other parameters. Critical parameters are the drag coefficient of canopy elements in each layer $\left(c_{\mathrm{d}}=0.25\right)$, the value of $u_{*} / u(h)$ for neutral conditions $\left(\beta_{\mathrm{N}}=0.35\right)$, and the Schmidt number at the canopy top with a nominal value $S c=0.5$ as modified for atmospheric stability using Eq. (A25). These parameters have physical meaning, are largely observable, have a welldefined range of observed values, and are not unconstrained parameters to fit the model to observations. The expressions for $\beta$ and $S c$ given by Eqs. (A22) and (A25) are observationally based but are nevertheless heuristic (Harman and Finnigan, 2007, 2008). The parameter $c_{2}$ relates to the depth scale of the RSL and though $c_{2}$ can have complex expressions, a simplification is to take $c_{2}=0.5$ (Harman and Finnigan, 2007, 2008; Harman, 2012). The canopy length scale $L_{\mathrm{c}}$ is assumed to be constant with height as in Eq. (A27) and is thought to be more conservative than either leaf area density or the leaf drag coefficient separately (Harman and Finnigan, 2007). Massman (1997) developed a first-order closure canopy turbulence parameterization that accounts for vertical variation in leaf area density, but that is not considered here.

The plant canopies simulated in this study are dense canopies in the sense that most of the momentum is absorbed by plant elements. Appendix A4 provides a modification for sparse canopies (e.g., plant area index $<1 \mathrm{~m}^{2} \mathrm{~m}^{-2}$ ) whereby $\beta$ decreases, but this extension to sparse canopies is largely untested. Raupach (1994) and Massman (1997) also decrease $\beta$ with sparse canopies. We note that the same challenge occurs in land surface models such as CLM4.5, with parameterizations to account for the effects of canopy denseness on within-canopy turbulence (Zeng et al., 2005).

The RSL parameterization has limits to its applicability; $L_{\mathrm{c}} / L$ must be greater than some critical value related to $\beta$ in unstable conditions and less than some critical value in stable conditions (Harman and Finnigan, 2007). We constrained $\beta$ to a value between 0.5 (unstable) and 0.2 (stable). In practice, this means that $L_{\mathrm{c}} / L \geq-0.79$ (unstable) and $L_{\mathrm{c}} / L \leq 3.75$ (stable), which satisfies the theoretical limits given by Harman and Finnigan (2007). This range of values for $\beta$ is consistent with observations above forest canopies shown in Harman and Finnigan (2007) and is comparable with other parameterizations. Data presented by Raupach (1994) show a similar range in $\beta$ for full plant canopies, and his parameterization has a maximum value of 0.3 . The parameterization of Massman (1997) of $\beta$ has a maximum value of 0.32 for full canopies, but he notes that other studies suggest a range of $0.15-0.25$ to 0.40 . The Harman and Finnigan (2007) param- 
eterization used here has the advantage of being consistent with current RSL theory (Raupach et al., 1996; Finnigan et al., 2009) and incorporates stability dependence through $\beta$, in contrast with Raupach (1994) and Massman (1997). Removing the lower limit $\beta \geq 0.2$ has little effect on the simulations, while the upper limit $\beta \leq 0.5$ acts to suppress daytime $u_{*}$ at some sites (not shown).

$l_{\mathrm{m}} / \beta$ is a critical length scale in the RSL theory. It modifies flux-profile relationships $\left(\hat{\phi}_{\mathrm{m}}, \hat{\phi}_{\mathrm{c}}\right)$ and also the profiles for $u$ and $K_{\mathrm{c}}$ in the canopy given by Eqs. (21) and (22). These latter profiles decline exponentially with greater depth in the canopy in relation to $l_{\mathrm{m}} / \beta$, which can be equivalently written as $0.5 c_{\mathrm{d}} a / \beta^{2}$ substituting $l_{\mathrm{m}}$ from Eq. (A26) and $L_{\mathrm{c}}$ from Eq. (A27). For a particular canopy defined by $c_{\mathrm{d}}$ and $a=\left(L_{\mathrm{T}}+S_{\mathrm{T}}\right) / h$, the exponential within-canopy profile is bounded by the limits placed on $\beta$. Further insight is gained from an equivalent form of the wind profile equation in which $u(z)=u(h) \exp [-\eta(1-z / h)]$ with $\eta=h \beta / l_{\mathrm{m}}$. A typical value of $\eta$ reported in observational studies is 24 (Thom, 1975; Cionco, 1978; Brutsaert, 1982). Comparing equations shows that $\eta=0.5 c_{\mathrm{d}}\left(L_{\mathrm{T}}+S_{\mathrm{T}}\right) / \beta^{2}$. The constraint $0.2 \leq \beta \leq 0.5$ places limits on $\eta$. The maximum plant area index in our simulations is $7.2 \mathrm{~m}^{2} \mathrm{~m}^{-2}$ at US-Dk2. With $c_{\mathrm{d}}=0.25, \eta$ has values from 3.6 to 22.5 . This allows for quite low wind speed and conductance within the canopy. Diabatic stability within the canopy can differ from that above the canopy. This would be reflected in the wind speeds used to calculate the leaf conductances and also the conductance network used to calculate within canopy scalar profiles. For these reasons, we employ minimum values to the withincanopy wind speed and aerodynamic conductances.

\section{Conclusion}

For over 30 years, land surface models have parameterized surface fluxes using a dual-source canopy in which vegetation is treated as a big leaf without vertical structure and in which MOST is used to parameterize turbulent fluxes above the canopy. The RSL parameterization of Harman and Finnigan $(2007,2008)$ provides a means to represent turbulent processes in a multilayer model extending from the ground through the canopy and the RSL with sound theoretical underpinnings of canopy-induced turbulence and with few additional parameters. The multilayer canopy improves model performance compared to CLM4.5 in terms of latent and sensible heat fluxes, friction velocity, and radiative temperature. Improvement in latent and sensible heat fluxes comes primarily from advances in modeling stomatal conductance and canopy physiology beyond what is in CLM4.5. These advances also improve friction velocity and radiative temperature, with additional improvement from the RSL parameterization. The multilayer model combines improvements in both leaf biophysics and canopy-induced turbulence and both contribute to the overall model improvement. Indeed, the modeling of canopy turbulence and canopy physiology are inextricably linked (Finnigan and Raupach, 1987), and the $30+$ years of land surface models have likely lead to compensating insufficiency in both.

Multilayer canopies are becoming practical for land surface models, seen in the ORCHIDEE-CAN model (Ryder et al., 2016; Chen et al., 2016) and in this study. A multilayer canopy facilitates the treatment of plant hydraulic control of stomatal conductance (Williams et al., 1996; Bonan et al., 2014), provides new ways to test models directly with leaf-level measurements in the canopy, and is similar to the canopy representations used in canopy-chemistry models (Stroud et al., 2005; Forkel et al., 2006; Wolfe and Thornton, 2011; Ashworth et al., 2015). Here, we provide a tractable means to simulate the necessary profiles of wind speed, temperature, and water vapor while also accounting for the RSL. While this is an advancement over CLM4.5, much work remains to fully develop this class of model and to implement the multilayer canopy parameterization in CLM. Significant questions remain about how well multilayer models capture the profiles of air temperature, water vapor, and leaf temperature in the canopy, how important these profiles are for vegetation source-sink fluxes, and how many canopy layers are needed to adequately represent gradients in the canopy. The testing of ORCHIDEE-CAN (Chen et al., 2016) has begun to address these questions, but highquality measurements in canopies are required to better distinguish among turbulence parameterizations (e.g., Patton et al., 2011). The canopy model described here represents a necessary approach to rigorously and comprehensively evaluate process parameterizations for consistency with observations and theory prior to implementation in a full land surface model, where confounding errors are likely to affect the results. Moreover, multilayer canopies raise a fundamental question about the interface between the atmosphere and land surface. The coupling of the Community Land Model with the atmosphere depicts the land as a bulk source-sink for heat, moisture, and momentum, and these fluxes are boundary conditions to the atmosphere model. Multilayer canopy models simulate a volume of air extending from some level in the atmosphere to the ground. A critical question that remains unresolved is where does the parameterization of the atmospheric boundary layer stop and the land surface model begin.

Code availability. The multilayer canopy runs independent of CLM4.5 but utilizes common code (e.g., soil temperature). The canopy flux code is available at https://github.com/gbonan/ CLM-ml_v0. 


\section{Appendix A: Model description}

\section{A1 Derivation of Eqs. (16) and (17)}

Equation (10) for the energy balance of the sunlit portion of layer $i$ can be algebraically rewritten as follows.

$T_{\ell \text { sun }, i}^{n+1}=\alpha_{i}^{\text {sun }} \theta_{i}^{n+1}+\beta_{i}^{\text {sun }} q_{i}^{n+1}+\delta_{i}^{\text {sun }}$

with

$\alpha_{i}^{\text {sun }}=\frac{2 c_{\mathrm{p}} g_{\mathrm{b}, i}}{2 c_{\mathrm{p}} g_{\mathrm{b}, i}+\lambda s_{i}^{\text {sun }} g_{\ell \text { sun }, i}+c_{\mathrm{L}, i} / \Delta t}$

$\beta_{i}^{\text {sun }}=\frac{\lambda g_{\ell \operatorname{sun}, i}}{2 c_{\mathrm{p}} g_{\mathrm{b}, i}+\lambda s_{i}^{\text {sun }} g_{\ell \text { sun }, i}+c_{\mathrm{L}, i} / \Delta t}$

$\delta_{i}^{\text {sun }}=$

$\frac{R_{\mathrm{n} \ell \text { sun }, i}-\lambda\left[q_{\mathrm{sat}}\left(T_{\ell \text { sun }, i}^{n}\right)-s_{i}^{\mathrm{sun}} T_{\ell \text { sun }, i}^{n}\right] g_{\ell \text { sun }, i}+c_{\mathrm{L}, i} T_{\ell \text { sun }, i}^{n} / \Delta t}{2 c_{\mathrm{p}} g_{\mathrm{b}, i}+\lambda s_{i}^{\mathrm{sun}} g_{\ell \operatorname{sun}, i}+c_{\mathrm{L}, i} / \Delta t}$

Similar coefficients are found from Eq. (13) for the shaded leaf to give

$T_{\ell \text { sha }, i}^{n+1}=\alpha_{i}^{\text {sha }} \theta_{i}^{n+1}+\beta_{i}^{\text {sha }} q_{i}^{n+1}+\delta_{i}^{\text {sha }}$.

Equation (14) for the ground surface energy balance is similarly rewritten as follows.

$T_{0}^{n+1}=\alpha_{0} \theta_{1}^{n+1}+\beta_{0} q_{1}^{n+1}+\delta_{0}$

with

$$
\begin{aligned}
& \alpha_{0}=\frac{c_{\mathrm{p}} g_{\mathrm{a}, 0}}{c_{\mathrm{p}} g_{\mathrm{a}, 0}+\lambda h_{\mathrm{s} 0} s_{0} g_{\mathrm{s} 0}+\kappa_{\mathrm{soil}} / \Delta z_{\mathrm{soil}}} \\
& \beta_{0}=\frac{\lambda g_{\mathrm{s} 0}}{c_{\mathrm{p}} g_{\mathrm{a}, 0}+\lambda h_{\mathrm{s} 0} s_{0} g_{\mathrm{s} 0}+\kappa_{\mathrm{soil}} / \Delta z_{\mathrm{soil}}} \\
& \delta_{0}= \\
& R_{\mathrm{n} 0}-\lambda h_{\mathrm{s} 0}\left[q_{\mathrm{sat}}\left(T_{0}^{n}\right)-s_{0} T_{0}^{n}\right] g_{\mathrm{s} 0}+T_{\mathrm{soil}}^{n} \kappa_{\text {soil }} / \Delta z_{\mathrm{soil}} \\
& c_{\mathrm{p}} g_{\mathrm{a}, 0}+\lambda h_{\mathrm{s} 0} s_{0} g_{\mathrm{s} 0}+\kappa_{\mathrm{soil}} / \Delta z_{\mathrm{soil}}
\end{aligned}
$$

With these substitutions, Eqs. (8) and (9) are rewritten as Eqs. (16) and (17) with the algebraic coefficients in Sect. S2.

\section{A2 Roughness sublayer parameterization}

The flux-gradient relationships used with Monin-Obukhov similarity theory are

$\phi_{\mathrm{m}}(\zeta)= \begin{cases}(1-16 \zeta)^{-1 / 4} & \zeta<0 \text { (unstable) } \\ 1+5 \zeta & \zeta \geq 0 \text { (stable) }\end{cases}$

for momentum, and

$\phi_{\mathrm{c}}(\zeta)= \begin{cases}(1-16 \zeta)^{-1 / 2} & \zeta<0 \text { (unstable) } \\ 1+5 \zeta & \zeta \geq 0 \text { (stable) }\end{cases}$ for heat and water vapor. These relationships use the dimensionless parameter $\zeta=(z-d) / L_{\mathrm{MO}}$. The integrated similarity functions are

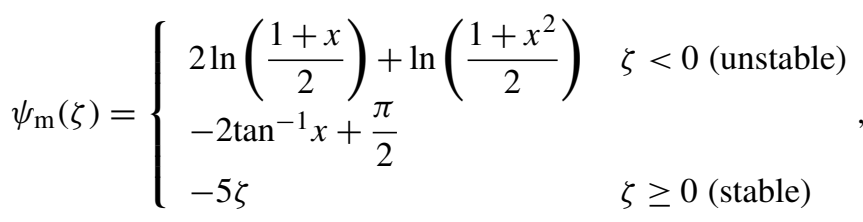

with $x=(1-16 \zeta)^{1 / 4}$, and

$\psi_{\mathrm{c}}(\zeta)=\left\{\begin{array}{ll}2 \ln \left(\frac{1+x^{2}}{2}\right) & \zeta<0 \text { (unstable) } \\ -5 \zeta & \zeta \geq 0 \text { (stable) }\end{array}\right.$.

These equations are valid for moderate values of $\zeta$ from about -2 to 1 (Foken, 2006), and we adopt a similar restriction.

The RSL parameterization modifies Monin-Obukhov similarity theory by introducing an additional dimensionless parameter $\xi=(z-d) \beta / l_{\mathrm{m}}$, which is the height $z-d$ normalized by the length scale $l_{\mathrm{m}} / \beta$. In Harman and Finnigan (2007, 2008), the modified flux-gradient relationship for momentum is

$\Phi_{\mathrm{m}}(z)=\phi_{\mathrm{m}}\left(\frac{z-d}{L_{\mathrm{MO}}}\right) \hat{\phi}_{\mathrm{m}}\left(\frac{z-d}{l_{\mathrm{m}} / \beta}\right)$

with

$\hat{\phi}_{\mathrm{m}}(\xi)=1-c_{1} \exp \left(-c_{2} \xi\right)$

and

$c_{1}=\left[1-\frac{k}{2 \beta} \phi_{\mathrm{m}}^{-1}\left(\frac{h-d}{L_{\mathrm{MO}}}\right)\right] \exp \left(c_{2} / 2\right)$,

and a simplification is to take $c_{2}=0.5$. The integrated RSL function $\hat{\psi}_{\mathrm{m}}$ is

$\hat{\psi}_{\mathrm{m}}(z)=\int_{z-d}^{\infty} \phi_{\mathrm{m}}\left(\frac{z^{\prime}}{L_{\mathrm{MO}}}\right)\left[1-\hat{\phi}_{\mathrm{m}}\left(\frac{z^{\prime}}{l_{\mathrm{m}} / \beta}\right)\right] \frac{\mathrm{d} z^{\prime}}{z^{\prime}}$.

For scalars, the flux-gradient relationship in Harman and Finnigan (2008) is

$\Phi_{\mathrm{c}}(z)=\phi_{\mathrm{c}}\left(\frac{z-d}{L_{\mathrm{MO}}}\right) \hat{\phi}_{\mathrm{c}}\left(\frac{z-d}{l_{\mathrm{m}} / \beta}\right)$.

The RSL function $\hat{\phi}_{\mathrm{c}}$ is evaluated the same as for $\hat{\phi}_{\mathrm{m}}$ using Eq. (A15), but with

$c_{1}=\left[1-\frac{S c k}{2 \beta} \phi_{\mathrm{c}}^{-1}\left(\frac{h-d}{L_{\mathrm{MO}}}\right)\right] \exp \left(c_{2} / 2\right)$. 
$\hat{\psi}_{\mathrm{c}}$ is evaluated similar to $\hat{\psi}_{\mathrm{m}}$ using Eq. (A17), but with $\phi_{\mathrm{c}}$ and $\hat{\phi}_{\mathrm{c}}$.

The functions $\hat{\psi}_{\mathrm{m}}$ and $\hat{\psi}_{\mathrm{c}}$ must be integrated using numerical methods. In practice, however, values can be obtained from a lookup table. Equation (A17) can be expanded using Eq. (A15) for $\hat{\phi}_{\mathrm{m}}$ and using $l_{\mathrm{m}} / \beta=2(h-d)$ from Eq. (A28) so that an equivalent equation is

$\hat{\psi}_{\mathrm{m}}(z)=c_{1} \int_{z-d}^{\infty} \phi_{m}\left(\frac{z^{\prime}}{L_{\mathrm{MO}}}\right) \exp \left[\frac{-c_{2} z^{\prime}}{2(h-d)}\right] \frac{\mathrm{d} z^{\prime}}{z^{\prime}}$.

The lower limit of integration in Eq. (A20) can be rewritten as $z-d=(z-h)+(h-d)$ and dividing both sides by $h-$ $d$ gives the expression $(z-h) /(h-d)+1$. In this notation, Eq. (A20) becomes

$$
\hat{\psi}_{\mathrm{m}}(z)=c_{1} \int_{\frac{z-h}{h-d}+1}^{\infty} \phi_{\mathrm{m}}\left[\frac{(h-d) z^{\prime}}{L_{\mathrm{MO}}}\right] \exp \left(-\frac{c_{2} z^{\prime}}{2}\right) \frac{\mathrm{d} z^{\prime}}{z^{\prime}} .
$$

In this equation, the integral is specified in a nondimensional form and depends on two nondimensional parameters: $(z-$ $h) /(h-d)$ and $(h-d) / L_{\mathrm{MO}}$. The integral is provided in a lookup table as $A\left[(z-h) /(h-d),(h-d) / L_{\mathrm{MO}}\right] . \hat{\psi}_{\mathrm{m}}$ is then given by $c_{1} A$. A similar approach gives $\hat{\psi}_{\mathrm{c}}$.

An expression for $\beta$ is obtained from the relationship

$\beta \phi_{\mathrm{m}}\left(\beta^{2} L_{\mathrm{c}} / L_{\mathrm{MO}}\right)=\beta_{\mathrm{N}}$,

with $\beta_{\mathrm{N}}$ the value of $u_{*} / u(h)$ for neutral conditions (a representative value is $\beta_{\mathrm{N}}=0.35$, which is used here). Using Eq. (A10) for $\phi_{\mathrm{m}}$, the expanded form of Eq. (A22) for unstable conditions $\left(L_{\mathrm{MO}}<0\right)$ is a quadratic equation for $\beta^{2}$ given by

$$
\left(\beta^{2}\right)^{2}+16 \frac{L_{\mathrm{c}}}{L_{\mathrm{MO}}} \beta_{\mathrm{N}}^{4}\left(\beta^{2}\right)-\beta_{\mathrm{N}}^{4}=0 .
$$

The correct solution is the larger of the two roots. For stable conditions ( $\left.L_{\mathrm{MO}}>0\right)$, a cubic equation is obtained for $\beta$ whereby

$5 \frac{L_{\mathrm{c}}}{L_{\mathrm{MO}}} \beta^{3}+\beta-\beta_{\mathrm{N}}=0$.

This equation has one real root. We restrict $\beta$ to be in the range $0.2-0.5$ (see Sect. 5 for further details).

The Schmidt number $(S c)$ is parameterized by Harman and Finnigan (2008) as

$S c=0.5+0.3 \tanh \left(2 L_{\mathrm{c}} / L_{\mathrm{MO}}\right)$.

Equation (21) is derived from the momentum balance equation with a first-order turbulence closure in which the eddy diffusivity is specified in relation to a mixing length $\left(l_{\mathrm{m}}\right)$ that is constant with height. From this, Harman and Finnigan (2007) obtained expressions for $l_{\mathrm{m}}$ and $d$ so that

$l_{\mathrm{m}}=2 \beta^{3} L_{\mathrm{c}}$,

with

$L_{\mathrm{c}}=\left(c_{\mathrm{d}} a\right)^{-1}$

and

$h-d=\frac{l_{\mathrm{m}}}{2 \beta}=\beta^{2} L_{\mathrm{c}}$.

The term $L_{\mathrm{c}}$ is the canopy length scale (m), specified by the dimensionless leaf aerodynamic drag coefficient (a common value is $c_{\mathrm{d}}=0.25$, which is used here) and plant area density $\left(a, \mathrm{~m}^{2} \mathrm{~m}^{-3}\right)$. For Eq. (A27), plant area density is estimated as the leaf and stem area index $\left(L_{\mathrm{T}}+S_{\mathrm{T}}\right)$ divided by canopy height $(h)$.

\section{A3 Obukhov length}

The Obukhov length is

$L_{\mathrm{MO}}=\frac{u_{*}^{2} \theta_{\mathrm{vref}}}{\operatorname{kg} \theta_{\mathrm{v} *}}$,

with $\theta_{\text {vref }}$ the virtual potential temperature $(\mathrm{K})$ at the reference height, and $\theta_{\mathrm{v} *}$ the virtual potential temperature scale (K) given as

$\theta_{\mathrm{v} *}=\theta_{*}+0.61 \theta_{\mathrm{ref}} q_{* \mathrm{~kg}}$.

The solution to $L_{\mathrm{MO}}$ requires an iterative numerical calculation (Fig. 2). A value for $\beta$ is obtained for an initial estimate of $L_{\mathrm{MO}}$ using Eq. (A22), which gives the displacement height $(d)$ using Eq. (A28). The Schmidt number $(S c)$ is calculated for the current $L_{\mathrm{MO}}$ using Eq. (A25). The functions $\phi_{\mathrm{m}}$ and $\phi_{\mathrm{c}}$ are evaluated using Eqs. (A10) and (A11) at the canopy height $(h)$ to obtain the parameter $c_{1}$ as in Eqs. (A16) and (A19). The similarity functions $\psi_{\mathrm{m}}$ and $\psi_{\mathrm{c}}$ are evaluated at $z$ and $h$ using Eqs. (A12) and (A13). The RSL functions $\hat{\psi}_{\mathrm{m}}$ and $\hat{\psi}_{\mathrm{c}}$ are evaluated at $z$ and $h$ from a lookup table. $u_{*}$ is obtained from Eq. (19) using the wind speed $\left(u_{\text {ref }}\right)$ at the reference height $\left(z_{\text {ref }}\right) . \theta_{*}$ is calculated from Eq. (20) using $\theta_{\text {ref }}$ for the current time step and $\theta(h)$ for the previous sub-time step, and a comparable equation provides $q_{*}$. A new estimate of $L_{\mathrm{MO}}$ is obtained, and the iteration is repeated until convergence in $L_{\mathrm{MO}}$ is achieved.

\section{A4 Sparse canopies}

The RSL theory of Harman and Finnigan $(2007,2008)$ was developed for dense canopies. Sparse canopies can be represented by adjusting $\beta_{\mathrm{N}}, d$, and $S c$ for plant area index $\left(L_{\mathrm{T}}+S_{\mathrm{T}}\right)$. The neutral value for $\beta$ is

$\beta_{\mathrm{N}}=\left[c_{\beta}+0.3\left(L_{\mathrm{T}}+S_{\mathrm{T}}\right)\right]^{1 / 2} \leq \beta_{\mathrm{N}_{\max }}$, 
where

$c_{\beta}=k^{2}\left[\ln \left(\frac{h+z_{0 \mathrm{~m}}}{z_{0 \mathrm{~m}}}\right)\right]^{-2}$

and $z_{0 \mathrm{~m}}=0.01 \mathrm{~m}$ is the roughness length for momentum of the underlying ground surface. $\beta_{\mathrm{N}}$ is constrained to be less than a maximum value for neutral conditions $\left(\beta_{\mathrm{N}_{\max }}=0.35\right)$. The displacement height is

$h-d=\beta^{2} L_{\mathrm{c}}\left\{1-\exp \left[-0.25\left(L_{\mathrm{T}}+S_{\mathrm{T}}\right) / \beta^{2}\right]\right\}$.
The Schmidt number is

$$
\begin{aligned}
& S c= \\
& \left(1-\frac{\beta_{\mathrm{N}}}{\beta_{\mathrm{N}_{\max }}}\right) 1.0+\frac{\beta_{\mathrm{N}}}{\beta_{\mathrm{N}_{\max }}}\left[0.5+0.3 \tanh \left(2 L_{\mathrm{c}} / L_{\mathrm{MO}}\right)\right] .
\end{aligned}
$$

This equation weights the Schmidt number between that for a neutral surface layer (1.0) and the RSL value calculated from Eq. (A25). 


\section{Appendix B: List of symbols, their definition, and units}

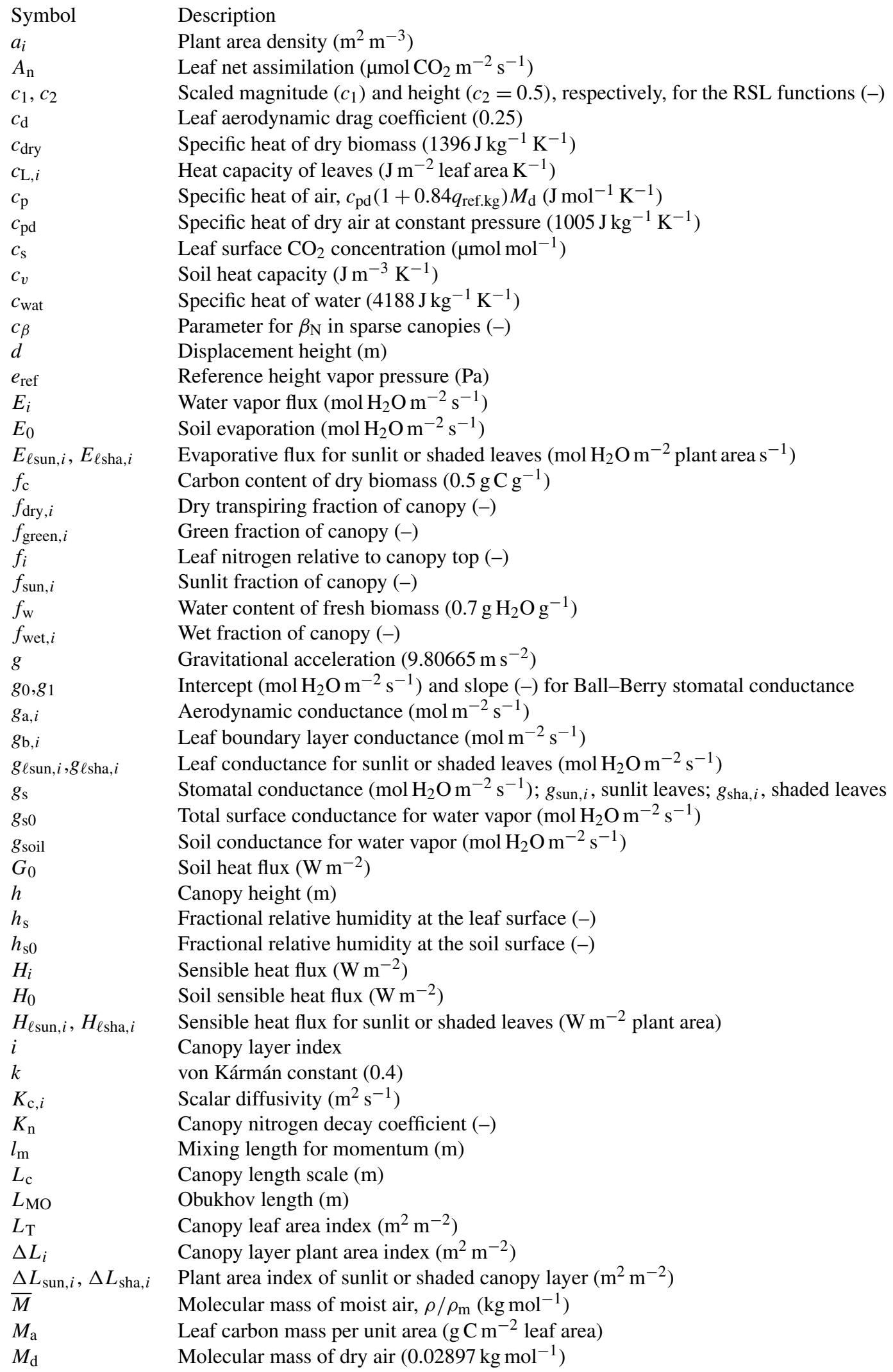




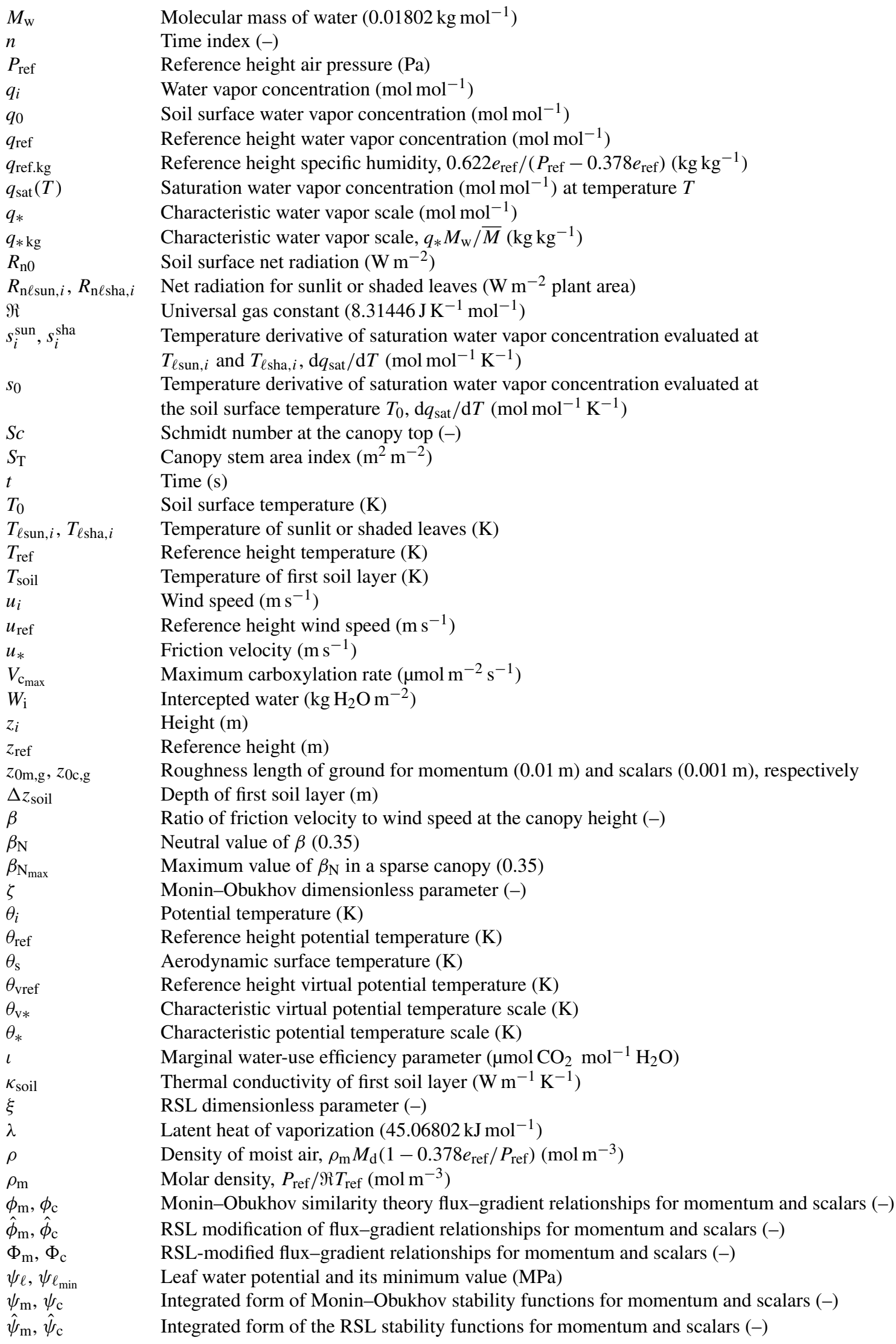




\section{The Supplement related to this article is available online at https://doi.org/10.5194/gmd-11-1467-2018- supplement.}

Author contributions. EP, IH, and JF developed the RSL code. GB developed the numerical solution for scalar profiles in the canopy. GB and EP implemented the code in the multilayer canopy. GB and EP designed the model simulations. KO performed the CLM4.5 simulations. YL provided the US-ARM data, and EB processed the US-Dk1, US-Dk2, and US-Dk3 data. GB wrote the paper with contributions from all co-authors.

Competing interests. The authors declare that they have no conflict of interest.

Acknowledgements. The National Center for Atmospheric Research is sponsored by the National Science Foundation. This work was supported by the National Science Foundation Science and Technology Center for Multi-Scale Modeling of Atmospheric Processes, managed by Colorado State University under cooperative agreement no. ATM-0425247.

Edited by: Chiel van Heerwaarden

Reviewed by: Metodija Shapkalijevski and one anonymous referee

\section{References}

Alkama, R. and Cescatti, A.: Biophysical climate impacts of recent changes in global forest cover, Science, 351, 600-604, 2016.

Ashworth, K., Chung, S. H., Griffin, R. J., Chen, J., Forkel, R., Bryan, A. M., and Steiner, A. L.: FORest Canopy Atmosphere Transfer (FORCAsT) 1.0: a 1-D model of biosphereatmosphere chemical exchange, Geosci. Model Dev., 8, 37653784, https://doi.org/10.5194/gmd-8-3765-2015, 2015.

Ball, M. C., Cowan, I. R., and Farquhar, G. D.: Maintenance of leaf temperature and the optimisation of carbon gain in relation to water loss in a tropical mangrove forest, Aust. J. Plant Physiol., 15, 263-276, 1988.

Blanken, P. D., Black, T. A., Yang, P. C., Neumann, H. H., Nesic, Z., Staebler, R., den Hartog, G., Novak, M. D., and Lee, X.: Energy balance and canopy conductance of a boreal aspen forest: partitioning overstory and understory components, J. Geophys. Res, 102, 28915-28927, 1997.

Bonan, G. B.: A Land Surface Model (LSM Version 1.0) for Ecological, Hydrological, and Atmospheric Studies: Technical Description and User's Guide, NCAR Tech. Note NCAR/TN417+STR, National Center for Atmospheric Research, Boulder, CO, 1996.

Bonan, G. B., Williams, M., Fisher, R. A., and Oleson, K. W.: Modeling stomatal conductance in the earth system: linking leaf water-use efficiency and water transport along the soil-plantatmosphere continuum, Geosci. Model Dev., 7, 2193-2222, https://doi.org/10.5194/gmd-7-2193-2014, 2014.
Brutsaert, W.: Evaporation into the Atmosphere: Theory, History, and Applications, Kluwer, Dordrecht, The Netherlands, 1982.

Burakowski, E., Tawfik, A., Ouimette, A., Lepine, L., Novick, K., Ollinger, S., Zarzycki, C., and Bonan, G.: The role of surface roughness, albedo, and Bowen ratio on ecosystem energy balance in the Eastern United States, Agr. For. Meteorol., 249, 367-367, 2018.

Chen, Y., Ryder, J., Bastrikov, V., McGrath, M. J., Naudts, K., Otto, J., Ottlé, C., Peylin, P., Polcher, J., Valade, A., Black, A., Elbers, J. A., Moors, E., Foken, T., van Gorsel, E., Haverd, V., Heinesch, B., Tiedemann, F., Knohl, A., Launiainen, S., Loustau, D., Ogée, J., Vessala, T., and Luyssaert, S.: Evaluating the performance of land surface model ORCHIDEE-CAN v1.0 on water and energy flux estimation with a single- and multilayer energy budget scheme, Geosci. Model Dev., 9, 2951-2972, https://doi.org/10.5194/gmd-9-2951-2016, 2016.

Choudhury, B. J. and Monteith, J. L.: A four-layer model for the heat budget of homogeneous land surfaces, Q. J. Roy. Meteor. Soc., 114, 373-398, 1988.

Cionco, R. M.: A mathematical model for air flow in a vegetative canopy, J. Appl. Meteorol., 4, 517-522, 1965.

Cionco, R. M.: Analysis of canopy index values for various canopy densities, Bound.-Lay. Meteorol., 15, 81-93, 1978.

Clark, M. P., Nijssen, B., Lundquist, J. D., Kavetski, D., Rupp, D. E., Woods, R. A., Freer, J. E., Gutmann, E. D., Wood, A. W., Gochis, D. J., Rasmussen, R. M., Tarboton, D. G., Mahat, V., Flerchinger, G. N., and Marks, D. G.: A unified approach for process-based hydrologic modeling: 2 . Model implementation and case studies, Water Resour. Res., 51, 2515-2542, https://doi.org/10.1002/2015WR017200, 2015.

Dai, Y., Dickinson, R. E., and Wang, Y.-P.: A two-big-leaf model for canopy temperature, photosynthesis, and stomatal conductance, J. Climate, 17, 2281-2299, 2004.

Deardorff, J. W.: Efficient prediction of ground surface temperature and moisture, with inclusion of a layer of vegetation, J. Geophys. Res., 83, 1889-1903, 1978.

De Frenne, P., Rodríguez-Sánchez, F., Coomes, D. A., Baeten, L., Verstraeten, G., Vellend, M., Bernhardt-Römermann, M., Brown, C. D., Brunet, J., Cornelis, J., Decocq, G. M., Dierschke, H., Eriksson, O., Gilliam, F. S., Hédl, R., Heinken, T., Hermy, M., Hommel, P., Jenkins, M. A., Kelly, D. L., Kirby, K. J., Mitchell, F. J. G., Naaf, T., Newman, M., Peterken, G., Petřík, P., Schultz, J., Sonnier, G., Van Calster, H., Waller, D. M., Walther, G.-R., White, P. S., Woods, K. D., Wulf, M., Graae, B. J., and Verheyen, K.: Microclimate moderates plant responses to macroclimate warming, P. Natl. Acad. Sci. USA, 110, 18561-18565, 2013.

Dickinson, R. E., Henderson-Sellers, A., Kennedy, P. J., and Wilson, M. F.: Biosphere-Atmosphere Transfer Scheme (BATS) for the NCAR Community Climate Model, NCAR Tech. Note NCAR/TN-275+STR, National Center for Atmospheric Research, Boulder, CO, 1986.

Dolman, A. J.: A multiple-source land surface energy balance model for use in general circulation models, Agr. Forest Meteorol., 65, 21-45, 1993.

Finnigan J. J. and Raupach M. R.: Transfer processes in plant canopies in relation to stomatal characteristics, in: Stomatal Function, edited by: Zeiger, E., Farquhar, G. D., and Cowan, I. R., Stanford University Press, Stanford, Calif., 385-429, 1987. 
Finnigan, J. J., Shaw, R. H., and Patton, E. G.: Turbulence structure above a vegetation canopy, J. Fluid Mech., 637, 387-424, 2009.

Foken, T.: 50 years of the Monin-Obukhov similarity theory, Bound.-Lay. Meteorol., 119, 431-447, 2006.

Forkel, R., Klemm, O., Graus, M., Rappenglück, B., Stockwell, W. R., Grabmer, W., Held, A., Hansel, A., and Steinbrecher, R.: Trace gas exchange and gas phase chemistry in a Norway spruce forest: A study with a coupled 1-dimensional canopy atmospheric chemistry emission model, Atmos. Environ., 40, S28S42, 2006.

Franks, P. J., Berry, J. A., Lombardozzi, D. L., and Bonan, G. B.: Stomatal function across temporal and spatial scales: deep-time trends, land-atmosphere coupling and global models, Plant Physiology, 174, 583-602, 2017.

Friedlingstein, P., Cox, P., Betts, R., Bopp, L., von Bloh, W., Brovkin, V., Cadule, P., Doney, S., Eby, M., Fung, I., Bala, G., John, J., Jones, C., Joos, F., Kato, T., Kawamiya, M., Knorr, W., Lindsay, K., Matthews, H. D., Raddatz, T., Rayner, P., Reick, C., Roeckner, E., Schnitzler, K.-G., Schnur, R., Stassmann, K., Weaver, A. J., Yoshikawa, C., and Zeng, N.: Climate-carbon cycle feedback analysis: results from the $\mathrm{C}^{4} \mathrm{MIP}$ model intercomparison, J. Climate, 19, 3337-3353, 2006.

Friedlingstein, P., Meinshausen, M., Arora, V. K., Jones, C. D., Anav, A., Liddicoat, S. K., and Knutti, R.: Uncertainties in CMIP5 climate projections due to carbon cycle feedbacks, J. Climate, 27, 511-526, 2014.

Garratt, J. R.: Flux profile relations above tall vegetation, Q. J. Roy. Meteor. Soc., 104, 199-211, 1978.

Geiger, R.: Das Klima der bodennahen Luftschicht, Friedr. Vieweg \& Sohn, Braunschweig, Germany, 1927.

Harman, I. N.: The role of roughness sublayer dynamics within surface exchange schemes, Bound.-Lay. Meteorol., 142, 1-20, 2012.

Harman, I. N. and Finnigan, J. J.: A simple unified theory for flow in the canopy and roughness sublayer, Bound.-Lay. Meteorol., 123, 339-363, 2007.

Harman, I. N. and Finnigan, J. J.: Scalar concentration profiles in the canopy and roughness sublayer, Bound.-Lay. Meteorol., 129, 323-351, 2008.

Haverd, V., Leuning, R., Griffith, D., van Gorsel, E., and Cuntz, M.: The turbulent Lagrangian time scale in forest canopies constrained by fluxes, concentrations and source distributions, Bound.-Lay. Meteorol., 130, 209-228, 2009.

Hollinger, S. E., Bernacchi, C. J., and Meyers, T. P.: Carbon budget of mature no-till ecosystem in North Central Region of the United States, Agr. Forest Meteorol., 130, 59-69, 2005.

Inoue, E.: On the turbulent structure of airflow within crop canopies, J. Meteorol. Soc. Japan Ser. II, 41, 317-326, 1963.

Jarvis, P. G. and McNaughton, K. G.: Stomatal control of transpiration: scaling up from leaf to region, Adv. Ecol. Res., 15, 1-49, 1986.

Juang, J.-Y., Katul, G. G., Siqueira, M. B., Stoy, P. C., and McCarthy, H. R.: Investigating a hierarchy of Eulerian closure models for scalar transfer inside forested canopies, Bound.-Lay. Meteorol, 128, 1-32, 2008.

Kucharik, C. J. and Twine, T. E.: Residue, respiration, and residuals: evaluation of a dynamic agroecosystem model using eddy flux measurements and biometric data, Agr. Forest Meteorol., 146, 134-158, 2007.
Kucharik, C. J., Norman, J. M., and Gower, S. T.: Measurements of branch area and adjusting leaf area index indirect measurements, Agr. Forest Meteorol., 91, 69-88, 1998.

Levis, S., Bonan, G. B., Kluzek, E., Thornton, P. E., Jones, A., Sacks, W. J., and Kucharik, C. J.: Interactive crop management in the Community Earth System Model (CESM1): seasonal influences on land-atmosphere fluxes, J. Climate, 25, 4839-4859, 2012.

Lu, Y., Williams, I. N., Bagley, J. E., Torn, M. S., and Kueppers, L. M.: Representing winter wheat in the Community Land Model (version 4.5), Geosci. Model Dev., 10, 1873-1888, https://doi.org/10.5194/gmd-10-1873-2017, 2017.

Mahat, V., Tarboton, D. G., and Molotch, N. P.: Testing above- and below-canopy representations of turbulent fluxes in an energy balance snowmelt model, Water Resour. Res., 49, 1107-1122, https://doi.org/10.1002/wrcr.20073, 2013.

Massman, W. J.: An analytical one-dimensional model of momentum transfer by vegetation of arbitrary structure, Bound.-Lay. Meteorol., 83, 407-421, 1997.

Massman, W. J. and Weil, J. C.: An analytical one-dimensional second-order closure model of turbulence statistics and the Lagrangian time scale within and above plant canopies of arbitrary structure, Bound.-Lay. Meteorol., 91, 81-107, 1999.

McNaughton, K. G. and van den Hurk, B. J. J. M.: A "Lagrangian" revision of the resistors in the two-layer model for calculating the energy budget of a plant canopy, Bound.-Lay. Meteorol., 74, 261-288, 1995.

Meyers, T. P. and Hollinger, S. E.: An assessment of storage terms in the surface energy balance of maize and soybean, Agr. Forest Meteorol., 125, 105-115, 2004.

Meyers, T. P., Finkelstein, P., Clarke, J., Ellestad, T. G., and Sims, P. F.: A multilayer model for inferring dry deposition using standard meteorological measurements, J. Geophys. Res., 103, 22645-22661, 1998.

Niinemets, Ü.: Components of leaf dry mass per area - thickness and density - alter leaf photosynthetic capacity in reverse directions in woody plants, New Phytol., 144, 35-47, 1999.

Niu, G.-Y. and Yang, Z.-L.: Effects of vegetation canopy processes on snow surface energy and mass balances, J. Geophys. Res., 109, D23111, https://doi.org/10.1029/2004JD004884, 2004.

Norman, J. M.: Modeling the complete crop canopy, in: Modification of the Aerial Environment of Plants, edited by: Barfield, B. J. and Gerber, J. F., American Society of Agricultural Engineers, St. Joseph, Michigan, 249-277, 1979.

Norman, J. M. and Jarvis, P. G.: Photosynthesis in Sitka spruce (Picea sitchensis (Bong.) Carr.), III. Measurements of canopy structure and interception of radiation, J. Appl. Ecol., 11, 375398, 1974.

Novick, K. A., Stoy, P. C., Katul, G. G., Ellsworth, D. S., Siqueira, M. B. S., Juang, J., and Oren, R.: Carbon dioxide and water vapor exchange in a warm temperate grassland, Oecologia, 138, 259274, 2004.

Oleson, K. W., Lawrence, D. M., Bonan, G. B., Drewniak, B., Huang, M., Koven, C. D., Levis, S., Li, F., Riley, W. J., Subin, Z. M., Swenson, S. C., Thornton, P. E., Bozbiyik, A., Fisher, R., Heald, C. L., Kluzek, E., Lamarque, J.-F., Lawrence, P. J., Leung, L. R., Lipscomb, W., Muszala, S., Ricciuto, D. M., Sacks, W., Sun, Y., Tang, J., and Yang, Z.-L.: Technical description of version 4.5 of the Community Land Model (CLM), NCAR 
Tech. note NCAR/TN-503+STR, National Center for Atmospheric Research, Boulder, Colorado, 2013.

Patton, E. G., Horst, T. W., Sullivan, P. P., Lenschow, D. H., Oncley, S. P., Brown, W. O., Burns, S. P., Guenther, A. B., Held, A., Karl, T., Mayor, S. D., Rizzo, L. V., Spuler, S. M., Sun, J., Turnipseed, A. A., Allwine, E. J., Edburg, S. L., Lamb, B. K., Avissar, R., Calhoun, R. J., Kleissl, J., Massman, W. J., Paw U. K. T., and Weil, J. C.: The Canopy Horizontal Array Turbulence Study, B. Am. Meteorol. Soc., 92, 593-611, 2011.

Physick, W. L. and Garratt, J. R.: Incorporation of a high-roughness lower boundary into a mesoscale model for studies of dry deposition over complex terrain, Bound.-Lay. Meteorol., 74, 55-71, 1995.

Pyles, R. D., Weare, B. C., and Paw U. K. T.: The UCD Advanced Canopy-Atmosphere-Soil Algorithm: comparisons with observations from different climate and vegetation regimes, Q. J. Roy. Meteor. Soc., 126, 2951-2980, 2000.

Raupach, M. R.: A practical Lagrangian method for relating scalar concentrations to source distributions in vegetation canopies, Q. J. Roy. Meteor. Soc., 115, 609-632, 1989.

Raupach, M. R.: Simplified expressions for vegetation roughness length and zero-plane displacement as functions of canopy height and area index, Bound.-Lay. Meteorol., 71, 211-216, 1994.

Raupach, M. R., Finnigan, J. J., and Brunet, Y.: Coherent eddies and turbulence in vegetation canopies: the mixing-length analogy, Bound.-Lay. Meteorol., 78, 351-382, 1996.

Raupach, M. R., Finkele, K., and Zhang, L.: SCAM (Soil-CanopyAtmosphere Model): Description and Comparisons with Field Data, Tech. Rep. No. 132, CSIRO Centre for Environmental Mechanics, Canberra, Australia, 1997.

Richardson, A. D., Hollinger, D. Y., Burba, G. G., Davis, K. J., Flanagan, L. B., Katul, G. G., Munger, J. W., Ricciuto, D. M., Stoy, P. C., Suyker, A. E., Verma, S. B., and Wofsy, S. C.: A multi-site analysis of random error in tower-based measurements of carbon and energy fluxes, Agr. Forest Meteorol., 136, 1-18, 2006.

Richardson, A. D., Aubinet, M., Barr, A. G., Hollinger, D. Y., Ibrom, A., Lasslop, G., and Reichstein, M.: Uncertainty quantification, in: Eddy Covariance: A Practical Guide to Measurement and Data Analysis, edited by: Aubinet, M., Vesala, T., and Papale, D., Springer, Dordrecht, 173-209, 2012.

Richtmyer, R. D. and Morton, K. W.: Difference Methods for Initial-Value Problems, 2nd edn., Wiley, New York, 1967.

Ryder, J., Polcher, J., Peylin, P., Ottlé, C., Chen, Y., van Gorsel, E., Haverd, V., McGrath, M. J., Naudts, K., Otto, J., Valade, A., and Luyssaert, S.: A multi-layer land surface energy budget model for implicit coupling with global atmospheric simulations, Geosci. Model Dev., 9, 223-245, https://doi.org/10.5194/gmd-9223-2016, 2016.

Ryu, Y., Baldocchi, D. D., Ma, S., and Hehn, T.: Interannual variability of evapotranspiration and energy exchange over an annual grassland in California, J. Geophys. Res., 113, D09104, https://doi.org/10.1029/2007JD009263, 2008.

Schaefer, K., Schwalm, C. R., Williams, C., Arain, M. A., Barr, A., Chen, J. M., Davis, K. J., Dimitrov, D., Hilton, T. W., Hollinger, D. Y., Humphreys, E., Poulter, B., Raczka, B. M., Richardson, A. D., Sahoo, A., Thornton, P., Vargas, R., Verbeeck, H., Anderson, R., Baker, I., Black, T. A., Bolstad, P., Chen, J., Curtis, P. S., Desai, A. R., Dietze, M., Dragoni, D., Gough, C.,
Grant, R. F., Gu, L., Jain, A., Kucharik, C., Law, B., Liu, S., Lokipitiya, E., Margolis, H. A., Matamala, R., McCaughey, J. H., Monson, R., Munger, J. W., Oechel, W., Peng, C., Price, D. T., Ricciuto, D., Riley, W. J., Roulet, N., Tian, H., Tonitto, C., Torn, M., Weng, E., and Zhou, X.: A model-data comparison of gross primary productivity: results from the North American Carbon Program site synthesis, J. Geophys. Res., 117, G03010, https://doi.org/10.1029/2012JG001960, 2012.

Scheffers, B. R., Phillips, B. L., Laurance, W. F., Sodhi, N. S., Diesmos, A., and Williams, S. E.: Increasing arboreality with altitude: a novel biogeographic dimension, P. Roy. Soc. B-Biol. Sci., 280, 20131581, https://doi.org/10.1098/rspb.2013.1581, 2013.

Sellers, P. J., Mintz, Y., Sud, Y. C., and Dalcher, A.: A simple biosphere model ( $\mathrm{SiB}$ ) for use within general circulation models, J. Atmos. Sci., 43, 505-531, 1986.

Sellers, P. J., Randall, D. A., Collatz, G. J., Berry, J. A., Field, C. B., Dazlich, D. A., Zhang, C., Collelo, G. D., and Bounoua, L.: A revised land surface parameterization $(\mathrm{SiB} 2)$ for atmospheric GCMs., Part I: Model formulation, J. Climate, 9, 676-705, 1996.

Shapkalijevski, M., Moene, A. F., Ouwersloot, H. G., Patton, E. G., and Vilà-Guerau de Arellano, J.: Influence of canopy seasonal changes on turbulence parameterization within the roughness sublayer over an orchard canopy, J. Appl. Meteor. Climatol., 55, 1391-1407, 2016.

Shaw, R. H. and Pereira, A. R.: Aerodynamic roughness of a plant canopy: a numerical experiment, Agr. Meteorol., 26, 51-65, 1982.

Shuttleworth, W. J. and Wallace, J. S.: Evaporation from sparse crops - an energy combination theory, Q. J. Roy. Meteor. Soc., 111, 839-855, 1985.

Siqueira, M., Leuning, R., Kolle, O., Kelliher, F. M., and Katul, G. G.: Modelling sources and sinks of $\mathrm{CO}_{2}, \mathrm{H}_{2} \mathrm{O}$ and heat within a Siberian pine forest using three inverse methods, Q. J. Roy. Meteor. Soc., 129, 1373-1393, 2003.

Staudt, K., Serafimovich, A., Siebicke, L., Pyles, R. D., and Falge, E.: Vertical structure of evapotranspiration at a forest site (a case study), Agr. Forest Meteorol., 151, 709-729, 2011.

Stoy, P. C., Katul, G. G., Siqueira, M. B. S., Juang, J.-Y., Novick, K. A., McCarthy, H. R., Oishi, A. C., Uebelherr, J. M., Kim, H.-S., and Oren, R.: Separating the effects of climate and vegetation on evapotranspiration along a successional chronosequence in the southeastern US, Global Change Biol., 12, 2115-2135, 2006.

Stroud, C., Makar, P., Karl, T., Guenther, A., Geron, C., Turnipseed, A., Nemitz, E., Baker, B., Potosnak, M., and Fuentes, J. D.: Role of canopy-scale photochemistry in modifying biogenicatmosphere exchange of reactive terpene species: Results from the CELTIC field study, J. Geophys. Res., 110, D17303, https://doi.org/10.1029/2005JD005775, 2005.

Taylor, K. E.: Summarizing multiple aspects of model performance in a single diagram, J. Geophys. Res., 106, 7183-7192, 2001.

Thom, A. S.: Momentum, mass and heat exchange of plant communities, in: Vegetation and the Atmosphere: vol. 1, Principles, edited by: Monteith, J. L., Academic Press, New York, 57-109, 1975.

Verma, S. B., Dobermann, A., Cassman, K. G., Walters, D. T., Knops, J. M., Arkebauer, T. J., Suyker, A. E., Burba, G. G., Amos, B., Yang, H., Ginting, D., Hubbard, K. G., Gitelson, A. A., and Walter-Shea, E. A.: Annual carbon dioxide exchange in 
irrigated and rainfed maize-based agroecosystems, Agr. Forest Meteorol., 131, 77-96, 2005.

Wang, Y.-P. and Leuning, R.: A two-leaf model for canopy conductance, photosynthesis and partitioning of available energy. I: Model description and comparison with a multi-layered model, Agr. Forest Meteorol., 91, 89-111, 1998.

Williams, M., Rastetter, E. B., Fernandes, D. N., Goulden, M. L., Wofsy, S. C., Shaver, G. R., Melillo, J. M., Munger, J. W., Fan, S.-M., and Nadelhoffer, K. J.: Modelling the soil-plantatmosphere continuum in a Quercus-Acer stand at Harvard Forest: the regulation of stomatal conductance by light, nitrogen and soil/plant hydraulic properties, Plant Cell Environ., 19, 911-927, 1996.
Wolfe, G. M. and Thornton, J. A.: The Chemistry of AtmosphereForest Exchange (CAFE) Model - Part 1: Model description and characterization, Atmos. Chem. Phys., 11, 77-101, https://doi.org/10.5194/acp-11-77-2011, 2011.

Wu, Y., Brashers, B., Finkelstein, P. L., and Pleim, J. E.: A multilayer biochemical dry deposition model, 1. Model formulation, J. Geophys. Res., 108, 4013, https://doi.org/10.1029/2002JD002293, 2003.

Zeng, X., Barlage, M., Dickinson, R. E., Dai, Y., Wang, G., and Oleson, K.: Treatment of undercanopy turbulence in land models, J. Climate, 18, 5086-5094, 2005. 